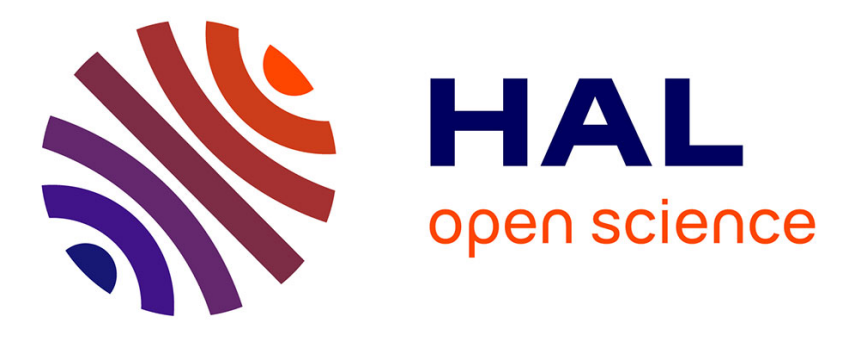

\title{
Process engineering for microbial production of 3-hydroxypropionic acid
}

Florence de Fouchécour, Ana-Karen Sánchez-Castañeda, Claire Saulou-Berion, Henry Eric Spinnler

\section{- To cite this version:}

Florence de Fouchécour, Ana-Karen Sánchez-Castañeda, Claire Saulou-Berion, Henry Eric Spinnler. Process engineering for microbial production of 3-hydroxypropionic acid. Biotechnology Advances, 2018, 36 (4), pp.1207-1222. 10.1016/j.biotechadv.2018.03.020 . hal-02128651

\section{HAL Id: hal-02128651 \\ https://hal.science/hal-02128651}

Submitted on 14 May 2019

HAL is a multi-disciplinary open access archive for the deposit and dissemination of scientific research documents, whether they are published or not. The documents may come from teaching and research institutions in France or abroad, or from public or private research centers.
L'archive ouverte pluridisciplinaire HAL, est destinée au dépôt et à la diffusion de documents scientifiques de niveau recherche, publiés ou non, émanant des établissements d'enseignement et de recherche français ou étrangers, des laboratoires publics ou privés. 
1 Process engineering for microbial production of 3-hydroxypropionic acid

Florence de Fouchécour ${ }^{\mathrm{a}}$, Ana-Karen Sánchez-Castañeda ${ }^{\mathrm{a}}$, Claire Saulou-Bérion ${ }^{\mathrm{a}}$, Henry Éric Spinnler ${ }^{\text {** }}$

${ }^{\text {a } U M R ~} 782$ GMPA, AgroParisTech, INRA, Université Paris Saclay, 78850 ThivervalGrignon, France

florence.de-salivet-de-fouchecour@inra.fr ana-karen.sanchez@inra.fr claire.saulou@agroparistech.fr

*corresponding author: spinnler@agroparistech.fr

\section{Abstract}

Due to concerns about the unsustainability and predictable shortage of fossil feedstocks, research efforts are currently being made to develop new processes for production of commodities using alternative feedstocks. 3-Hydroxypropionic acid (CAS 503-66-2) was recognised by the US Department of Energy as one of the most promising value-added chemicals that can be obtained from biomass. This article aims at reviewing the various strategies implemented thus far for 3-hydroxypropionic acid bioproduction. Special attention is given here to process engineering issues. The variety of possible metabolic pathways is also described in order to highlight how process design can be guided by their understanding. The most recent advances are described here in order to draw up a panorama of microbial 3hydroxypropionic acid production: best performances to date, remaining hurdles and foreseeable developments. Important milestones have been achieved, and process metrics are getting closer to commercial relevance. New strategies are continuously being developed that involve new microbial strains, new technologies, or new carbon sources in order to overcome the various hurdles inherent to the different microbial routes.

\section{Key-words}

3-hydroxypropionic acid, biosynthesis, bioconversion, fermentation, in situ product recovery, multi-step processes, metabolic routes 


\section{Introduction}

Since the advent of modern microbiology in the $19^{\text {th }}$ century, fermentative processes have been continuously improved and better understood. Microbial production of bulk chemicals was first attempted around a century ago (Buchholz and Collins, 2013). Still, development of bioprocesses for bulk chemical production remained limited throughout the $20^{\text {th }}$ century, because they were not competitive enough comparatively to chemical processes based on fossil feedstocks. However, petrochemical resources are bound to become scarce and their use was proven to contribute to global warming (IPCC, 2007). It has thus become a necessity to reduce dependency on non-renewable feedstocks and to start a transition towards a more sustainable, bio-based economy. Therefore, biotechnological processes for bulk chemical production have been gaining great interest over the past decades, and within the wider context of biorefinery (Choi et al., 2015).

In order to foster research in this field, the US Department of Energy (DoE) published a list of the most promising building-blocks that can be obtained from biomass (Bozell and Petersen, 2010; Werpy and Petersen, 2004). Thanks to its two functional groups (carboxyl and $\beta$ hydroxyl), 3-hydroxypropionic acid (3-HP, CAS 503-66-2) is a versatile molecule and has great potential for further transformation into useful chemicals. 3-HP was therefore included by the DoE in the top value added chemicals list (Werpy and Petersen, 2004). 3-HP applications can be divided into three categories: (i) direct use, (ii) polymerisation, and (iii) conversion to other value added chemicals. 3-HP can be used directly by the food and feed industry as an additive or as a preservative agent (Gokarn et al., 2002). It can also be polymerised to poly(3-hydroxypropionate) (poly(3-HP)) or to 3-HP containing co-polymers. In particular, poly(3-HP) has very promising properties and may become one alternative to fossil fuel-derived plastics (Andreeßen et al., 2014). Lastly, 3-HP can also be converted to numerous other useful chemicals, among which acrylic acid is the most noteworthy.

Figure 1 provides an overview of the chronology of research on 3-HP bioproduction. From the early nineties to the early 2000 s, research efforts remained low and focused mostly on the bacterial production of the 3-HP-containing polymer, poly(3-hydroxybutyrate-co-3hydroxypropionate) by Alcaligenes sp. (Cao et al., 1998; Nakamura et al., 1991; Wang et al., 2002, 1999). Since the early 2000s, research has been focusing more and more on 3-HP production using recombinant bacterial strains, mainly of Klebsiella pneumoniae and 
Escherichia coli (Gokarn et al., 2002; Suthers and Cameron, 2001). By considering the number of references in the Web of Science and the number of patents related to the bioproduction of 3-HP, it seems that the DoE report published in 2004 has indeed triggered research on this topic (see figure 1). For the last few years, approaches to 3-HP production have been diversifying. This is true on different levels: (i) new organisms have been tested and new metabolic pathways have been explored; (ii) different process modes have been implemented; and (iii) new - or emerging - technologies have been applied to the improvement of 3-HP production. The present study aims at reviewing the various process engineering strategies that were implemented for the purpose of 3-HP microbial production. To this end, present understanding of the different possible metabolic pathways is also reviewed in order to highlight how an understanding of the metabolism can help develop more efficient processes. This study also includes a review of available in situ product recovery (ISPR) processes and highlights the questions addressed by these methods.

\section{3-HP as microbial product: various routes with various hurdles}

One of the essential strategic choices when designing a new process for biobased chemicals production is to select a relevant microbial agent and an efficient metabolic pathway. Ideally the selected microorganism is an easy-to-use, non-pathogenic, genetically-stable microbe, and an efficient producer. In the case of 3-HP production, various approaches have been undertaken in order to develop microbial hosts suitable for such a process. Some of the best 3HP biosynthesis performances are summed up at Table 1. Here, we aim at providing an overview of the possible metabolic routes and of the main strategies that were implemented, for better understanding the rationale behind the various operational strategies that are being reviewed later in this article. Genetic engineering works for the purpose of 3-HP production were already reviewed extensively several times. For details on these, readers are therefore referred to more comprehensive reviews (David et al., 2017; Jiang et al., 2009; Kumar et al., 2013; Kumar and Park, 2017; Liu et al., 2017; Matsakas et al., 2014).

\subsection{Metabolic pathways for 3-HP production}

\subsubsection{Glycerol oxidation through a coenzyme A-dependent pathway}

3-HP is a natural end product of glycerol oxidation in Lactobacilli, which are obligate 
fermentative, Gram-positive bacteria. Glycerol metabolism was notably investigated in detail in Lactobacillus reuteri, a heterofermentative species living in human and animal gastrointestinal ecosystems (Kandler et al., 1980). This species cannot grow on glycerol as sole carbon or energy source (Sobolov and Smiley, 1960; Talarico et al., 1990). However, both resting (i.e. non-growing) cells and cells growing on other substrates (e.g. glucose or lactose) are able to consume glycerol. It is first dehydrated into 3-HPA in metabolosomes by a cobalamin (vitamin $\mathrm{B}_{12}$ )-dependent diol dehydratase (Sriramulu et al., 2008; Talarico and Dobrogosz, 1990). Then, in the case of growing cells of L. reuteri, 3-HPA is reduced to 1, 3PDO with consumption of one mole of reducing equivalent per mole of 1,3-PDO produced. 3HPA is used as electron acceptor for sugar fermentation. It leads to a fermentative shift from ethanol to the more oxidised product, acetate, thus stimulating cell growth from glucose (Talarico et al., 1990). On the other hand, when glycerol is supplied to resting cells, there is no such need for electron dissipation. 3-HPA is mainly accumulated in the medium (Krauter et al., 2012; Sardari et al., 2013; Talarico et al., 1988). However, 3-HP and 1,3-PDO are also found as by-products (Talarico et al., 1988). The reductive pathway (from 3-HPA to 1,3PDO) remains the same. An oxidative pathway is activated that converts 3-HPA into 3-HP. The aldehyde is converted to 3-HP through a coenzyme A (CoA)-dependent, ATP producing pathway (see Fig. 2.A) (Amin et al., 2013; Dishisha et al., 2014; Sabet-Azad et al., 2015). Sabet-Azad et al. successfully introduced this pathway into Escherichia coli. When resting cells were used, 3-HP was the only product obtained, while 1,3-PDO was found as co-product when growing cells were used instead (Sabet-Azad et al., 2015). 3-HPA oxidation and reduction are in redox balance, thus implying that the theoretical 3-HP yield from glycerol is limited to $\mathrm{Y}_{3-\mathrm{HP}}=0.5 \mathrm{~mol}_{3-\mathrm{HP}}$ molglycerol $^{-1}$, with 1,3-PDO as an obligate by-product. In practice, yields are even lower due to the accumulation of 3-HPA. Moreover, this aldehyde accumulation is deleterious to cells. When accumulated, monomeric 3-HPA is in equilibrium with its hydrated form and its cyclic dimeric form; the mixture of these with acrolein is called reuterin (Engels et al., 2016; Talarico and Dobrogosz, 1989). Due to the toxicity of reuterin, bioconversion of glycerol by L reuteri in batch mode stops within a few hours (Burgé et al., 2015).

The overall free energy liberation during conversion of glycerol into 3-HP is $\Delta \mathrm{rG}_{\text {glycerol } \rightarrow 3-\mathrm{HP}}^{\circ}=-50 \mathrm{~kJ} \mathrm{~mol}^{-1}$ (considering equation 1). Standard free energies were calculated using a group contribution method, according to Jankowski et al., 2008, and for the 
following conditions: $\mathrm{pH}=7$, zero ionic strength and a temperature of $298 \mathrm{~K}$. The pathway thus seems thermodynamically feasible, however, the penultimate step has a positive standard free energy release $\left(\Delta \mathrm{rG}_{3-\mathrm{HP}-\mathrm{CoA} \rightarrow 3-\mathrm{HP}-\mathrm{P}}^{\circ}=15 \mathrm{~kJ} \mathrm{~mol}^{-1}\right)$. Therefore, some bottlenecks might exist and further investigation would be necessary to identify in which conditions this step becomes favourable (Jiang et al., 2009; Mavrovouniotis, 1996). Despite the ATP formation accompanying 3-HP production, the metabolic route might not be energy-effective because of thermodynamic bottlenecks and because of the energetic cost for exporting products outside the cell (van Maris et al., 2004). This CoA-dependent pathway is also present in Klebsiella pneumoniae, along with the CoA-independent pathway (Kumar and Park, 2017). 3-HP production in K. pneumoniae is however mostly considered through the latter (part 2.1.2).

$\underset{\text { glycerol }}{\mathrm{C}_{3} \mathrm{H}_{8} \mathrm{O}_{3}}+\mathrm{ADP}^{2-}+\mathrm{HPO}_{4}^{2-}+\mathrm{NAD}^{+} \rightarrow \underset{3-H P}{\mathrm{C}_{3} \mathrm{H}_{5} \mathrm{O}_{3}^{-}}+\mathrm{ATP}^{3-}+\mathrm{H}_{2} \mathrm{O}+\mathrm{NADH}+\mathrm{H}^{+}$

\subsubsection{Glycerol oxidation through a coenzyme A-independent pathway}

Bacteria from genera Klebsiella, Clostridium, Enterobacter and Citrobacter are able to grow on glycerol during anaerobic fermentation. This property has typically been investigated for the purpose of 1,3-PDO production (Biebl et al., 1999). During glycerol fermentation, different metabolic routes are in redox balance with one another. Part of the glycerol is converted to more oxidised end products, such as lactate, succinate, formate, acetate and $\mathrm{CO}_{2}$. Biomass production from glycerol also produces reducing equivalents. Glycerol already being a very reduced carbon source $\left(4.67 \mathrm{e}^{-} / \mathrm{C}\right)$, its fermentation requires efficient routes for the dissipation of reducing equivalents. Possible end products depend on the microbial strain. For species like Klebsiella pneumoniae and Citrobacter freundii, 1,3-PDO is the main product along with acetate (Clomburg and Gonzalez, 2013), the 1,3-PDO pathway serving as the reducing equivalent dissipation pathway. 1,3-PDO production from glycerol is a two-step route (Biebl et al., 1999; Clomburg and Gonzalez, 2013), which makes it a quick way of dissipating electrons. The intermediary product between glycerol and 1,3-PDO is 3-HPA (Fig. 2.B). In some species, such as $K$. pneumoniae, this first step is catalysed by a vitamin $\mathrm{B}_{12-}$ dependent glycerol dehydratase. Despite 3-HPA being present as an intermediate, no significant amount of 3-HP is naturally produced by these microorganisms. 3-HP is not mentioned as an end product of glycerol fermentation (Biebl et al., 1999; Clomburg and 
Gonzalez, 2013) and, when given, mass balances close around $100 \%$ without any 3-HP (Moscoviz et al., 2016b). Nevertheless, K. pneumoniae was shown to possess a NAD ${ }^{+}-$ dependent aldehyde dehydrogenase that can use 3-HPA as a substrate and convert it to 3-HP (Raj et al., 2010). Aldehyde dehydrogenase overexpression is however required for 3-HP biosynthesis in significant amounts. The two successive reactions leading to 3-HP from glycerol both have negative free energy releases: $\Delta \mathrm{rG}_{\text {glycerol } \rightarrow 3-\mathrm{HPA}}^{\circ}=-38 \mathrm{~kJ} \mathrm{~mol}^{-1}$ and $\Delta \mathrm{rG}_{3-\mathrm{HPA} \rightarrow 3-\mathrm{HP}}^{\circ \prime}=-41 \mathrm{~kJ} \mathrm{~mol}^{-1}$. The overall free energy release is then $\Delta \mathrm{rG}_{\text {glycerol } \rightarrow 3-\mathrm{HP}}^{\circ}=-79$ $\mathrm{kJ} \mathrm{mol}^{-1}$ (see equation 2 for the stoechiometrics), so this pathway is thermodynamically favourable. Despite the standard free energy being negative, it is likely that thermodynamical barriers arise in non-respiratory conditions, due to less efficient $\mathrm{NAD}^{+}$regeneration.

$$
\underset{\text { glycerol }}{\mathrm{C}_{3} \mathrm{H}_{8} \mathrm{O}_{3}}+\mathrm{NAD}^{+} \rightarrow \underset{3-H P}{\mathrm{C}_{3} \mathrm{H}_{5} \mathrm{O}_{3}^{-}}+2 \mathrm{H}^{+}+\mathrm{NADH}
$$

$$
\text { CoA-independent 3-HP production from glycerol in K. pneumoniae is one of the most }
$$
intensively investigated strategies. Works on engineering K. pneumoniae for 3-HP synthesis were recently reviewed by Kumar et al. (Kumar and Park, 2017). It was identified that the limiting step of 3-HP production, is the conversion of 3-HPA by an aldehyde dehydrogenase (Y. Li et al., 2016). Efforts have therefore been made in order to engineer more efficient aldehyde dehydrogenases and to make this step more favourable. Li et al. carried a systematic optimization for 3-HP production by K. pneumoniae, taking multiple factors into account, such as promoter strength, metabolic pathway modifications, medium composition and operating parameters. Then the mutant strains were tested in a bioreactor, in fed-batch mode. They obtained the highest 3-HP titre so far: $83.8 \mathrm{~g} \mathrm{~L}^{-1}$ with a productivity of $1.16 \mathrm{~g} \mathrm{~L}^{-1} \mathrm{~h}^{-1}$ (Y. Li et al., 2016).

\section{This two-step, CoA-independent pathway has been implemented in other microbial hosts as} well. It is predominantly used when 3 -HP production from glycerol is considered with $E$. coli (David et al., 2017). This approach in E. coli led to one of the highest 3-HP titre so far and the highest obtained in this species (71.9 $\mathrm{g} \mathrm{L}^{-1}$, see Table 1). Chu et al. transformed E. coli W3110 with gabD4, a gene from Cupriavidus necator encoding a highly active aldehyde dehydrogenase. The enzyme activity was then improved by site-directed and saturation mutagenesis. During fed-batch conditions in a 5 L bioreactor, the most efficient mutant $E$. coli could produce 3 -HP up to $71.9 \mathrm{~g} \mathrm{~L}^{-1}$ with a productivity of $1.8 \mathrm{~g} \mathrm{~L}^{-1} \mathrm{~h}^{-1}$ (Chu et al., 2015). 
This CoA-independent pathway was also recently implemented in the industrial chassis Bacillus subtilis (Kalantari et al., 2017). B. subtilis was transformed with the two-step pathway from K. pneumoniae. Further optimization of medium composition and strain construction led to a stable genetic construction and a maximum 3-HP titre of $10 \mathrm{~g} \mathrm{~L}^{-1}$ in shake-flasks, with a 0.80 molc $_{\mathrm{C}} \mathrm{mol}_{\mathrm{C}}^{-1}$ yield.

Interestingly, this pathway was implemented in E. coli and Corynebacterium glutamicum for 3-HP synthesis from a mix of sugars, using glycerol only as an intermediate. Glucose and xylose were first converted to dihydroxyacetone (DHA) through glycolysis or pentose phosphate pathway, respectively. DHA was subsequently converted to glycerol through a synthetic pathway. 3-HP production was achieved from glycerol through the CoAindependent pathway (Z. Chen et al., 2017; Jung et al., 2015).

\subsubsection{Malonyl-coenzyme A pathway}

Among the various metabolic routes for 3-HP production from sugars, such as glucose, the malonyl-CoA pathway was the most studied until now (Table 1). The use of this pathway for 3-HP biosynthesis was already extensively reviewed (Liu et al., 2017). Glucose conversion to 3-HP through the malonyl-CoA pathway has typically been investigated in model organisms, such as E. coli, Saccharomyces cerevisiae (Liu et al., 2017), and more recently in the fission yeast Schizosaccharomyces pombe (Suyama et al., 2017). The first part of the pathway, from glucose to two acetyl-CoA (Fig. 2.C), is achieved through endogenous sugar catabolism, comprising glycolysis. Malonyl-CoA is then obtained from acetyl-CoA using an acetyl-CoA decarboxylase. The last two steps, from malonyl-CoA to 3-HP (Fig. 2.C), are both catalyzed by a malonyl-CoA reductase (MCR) from the cyanobacterium Chloroflexus aurantiacus. The MCR has two distinct functional domains: the first one is C-terminal and catalyses malonylCoA's reduction into malonate semialdehyde (MSA), the second one is N-terminal and catalyses MSA's reduction into 3-HP. It was shown that the overall enzymatic activity was increased when MCR was separated in two fragments, MCR-C and MCR-N. The MCR-C step was however found rate limiting, and one of the highest 3-HP titer for the malonyl-CoA pathway (40.6 $\mathrm{g} \mathrm{L}^{-1}$, see Table 1) was achieved thank to balancing both MCR-C and MCR-N enzyme activities.

The overall transformation of glucose to 3-HP is redox neutral, since both molecules have the 
same electron equivalent per carbon atom $\left(4 \mathrm{e}^{-/ C}\right)$. Consequently, this pathway does not require an effective dissipation of excess electrons, like pathways from glycerol do (see parts 2.1.1 and 2.1.2). In addition, the overall transformation of glucose into 3-HP is thermodynamically favourable, with a negative free energy release $\Delta \mathrm{rG}_{\mathrm{glucose} \rightarrow 3-\mathrm{HP}}^{\circ}=-182 \mathrm{~kJ}$ $\mathrm{mol}^{-1}$ (see equation 3 for stoichiometrics). A further advantage of the malonyl-CoA pathway is that it uses common metabolic intermediates, such as pyruvate and acetyl-CoA.

Consequently, a great variety of feedstocks could be considered for 3-HP production. The malonyl-CoA pathway was notably used for 3-HP biosynthesis from a mix of glucose and xylose in Saccharomyces cerevisiae (Kildegaard et al., 2015), from atmospheric carbon dioxide in cyanobacteria Synechocystis sp. PCC 6803 (Wang et al., 2016b) and Synechococcus elongatus (Lan et al., 2015), and more recently from methanol in Methylobacterium extorquens (Yang et al., 2017). However, a downside of resorting to common and central metabolic intermediates lies in the fact that there exist many competitive pathways. It leads to a broad range of by-products, thus limiting the maximal 3-HP yield from the substrate. Notably, acetate overflow is commonly observed when rapidly growing cells of E. coli are used. Moreover, malonyl-CoA is involved in the synthesis of fatty acids. It is thus necessary to implement strategies in order to limit the diversion of carbon flux towards other products. The highest performances obtained through the malonyl-CoA pathway were achieved by OPX Biotechnologies. Their work aims both at increasing MCR activity and at decreasing the fatty acid synthesis. They could reach a final 3-HP titre of $48.8 \mathrm{~g} \mathrm{~L}^{-1}$, with a

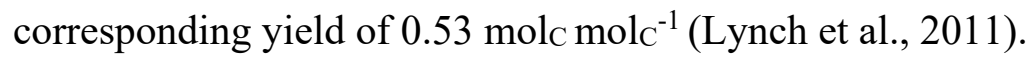

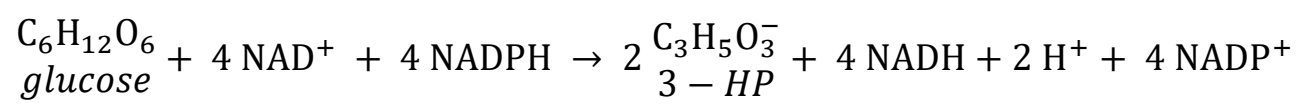

\subsection{4 $\beta$-alanine pathway}

Another strategy for 3-HP production from glucose was proposed in E. coli and S. cerevisiae, through the $\beta$-alanine pathway. This was first patented by Cargill in E. coli (Liao et al., 2005), and by Novozymes in S. cerevisiae (Jessen et al., 2012). Moreover, Novozymes recently patented a $\beta$-alanine pathway for various microbial hosts, both bacterial and fungic (Barnhart et al., 2015; Tassone and Diano, 2017). Glucose is first oxidised into pyruvate, which is subsequently converted to $\beta$-alanine. In turn, $\beta$-alanine is converted to malonic semi-aldehyde (MSA). This step also consumes an equivalent of pyruvate and releases an equivalent of L- 
alanine (Fig. 2.D). The L-alanine thus produced can be converted back into $\beta$-alanine using a 2,3-alanine aminomutase (Borodina et al., 2015). Finally, MSA is reduced to 3-HP. Borodina et al. used a genome-scale metabolic model and showed that the $\beta$-alanine route has a higher maximum theoretical 3-HP yield in comparison to the malonyl-CoA pathway, thus making it a more attractive route for an industrial process (Borodina et al., 2015). The maximal titre achieved in S. cerevisiae through this $\beta$-alanine pathway was reached in the same study by Borodina et al. They further optimised the expression of the critical enzymes and increased aspartate's synthesis. The S. cerevisiae strain they developed was implemented in fed-batch and reach a final titre of $13.7 \pm 0.3 \mathrm{~g} \mathrm{~L}^{-1}$, with a yield from glucose of $0.14 \pm 0.0$ molc $_{\mathrm{C}} \mathrm{mol}_{\mathrm{C}}{ }^{-1}$ (Borodina et al., 2015), which remains below the best performances achieved with the malonyl-CoA pathway (Table 1). Like the malonyl-CoA pathway, the $\beta$-alanine route uses common metabolic intermediates and can thus be used with other substrates than glucose. Indeed, attempt was made to produce 3-HP from xylose by Kildegaard et al. They compared S. cerevisiae strains harbouring either the malonyl-CoA or the $\beta$-alanine pathway. They showed that in batch mode, the $\beta$-alanine pathway achieved higher titres than the malonylCoA pathway: $6.09 \pm 0.33 \mathrm{~g} \mathrm{~L}^{-1}$ versus $2.30 \pm 0.09 \mathrm{~g} \mathrm{~L}^{-1}$ (Kildegaard et al., 2015). The malonyl-CoA and $\beta$-alanine pathways were also compared in the case of 3-HP production from atmospheric $\mathrm{CO}_{2}$ in Synechococcus elongatus (Lan et al., 2015). In this case, $\mathrm{CO}_{2}$ was first assimilated into phosphoenolpyruvate, which subsequently underwent either one of this pathway. In this study, the 3-HP titre was lower through the $\beta$-alanine pathway than through the malonyl-CoA pathway: $0.186 \mathrm{~g} \mathrm{~L}^{-1}$ versus $0.665 \mathrm{~g} \mathrm{~L}^{-1}$.

An alternative $\beta$-alanine pathway was developed by Song et al. They implemented a route where aspartate is obtained from fumarate instead of oxaloacetate (Fig. 2.D). They obtained higher performances than the oxaloacetate-based pathway. Their final engineered E. coli strains reached a $31.1 \mathrm{~g} \mathrm{~L}^{-1} 3$-HP titre in fed-batch mode, with a 0.423 molc molc $^{-1}$ yield from glucose (Table 1) (Song et al., 2016). As for the malonyl-CoA pathway, the fact that the $\beta$ alanine pathways uses common metabolic intermediates implies that many side-products are synthesised along with 3-HP. $\beta$-Alanine is notably a precursor of vitamin $\mathrm{B}_{5}$. Free energy release is not calculated here due to difficulties associated with the variety of possible routes and with the recycling of some of the intermediates.

\subsubsection{Aerobic 1,3-propanediol oxidation}


Acetic acid bacteria have been known since the beginning of modern microbiology for their ability to transform ethanol into acetic acid during vinegar production (Pasteur, 1864), but they are among the latest actors to have entered the scene of 3-HP production. These bacteria are Gram-negative, obligate aerobes, and are included in the Acetobacteraceae family. They possess various membrane-bound dehydrogenases, which gives them the ability to incompletely oxidise a broad range of alcohols and sugars directly in the periplasm (Deppenmeier and Ehrenreich, 2009). Of interest here is that some strains from genera Acetobacter and Gluconobacter were shown to selectively oxidise 1,3-PDO to 3-HP (Dishisha et al., 2015; J. Li et al., 2016). As first suggested by Dishisha et al. (Dishisha et al., 2015), the conversion is likely to occur similarly to that of ethanol into acetate, with two membrane-bound dehydrogenases involved (see Fig. 2.E). First a pyrroquinoline quinone (PQQ)-dependent alcohol dehydrogenase oxidises 1,3-PDO into 3-HPA (Adachi et al., 1978a, 1978b; Tkac et al., 2009). The aldehyde is then further oxidised into 3-HP by a PQQdependent aldehyde dehydrogenase (Adachi et al., 1980; Ameyama et al., 1981; Tkac et al., 2009). Each step releases two electrons that are transferred to dioxygen through the respiratory chain (Tkac et al., 2009). Thus, the molar yield Y3-HP/1,3-PDO is not redox limited and can theoretically reach 1.0 mol3-HP. $\mathrm{mol}_{1,3-\mathrm{PDO}^{-1}}$ when using resting cells. The overall free energy release is $\Delta \mathrm{rG}_{1,3-\mathrm{PDO} \rightarrow 3-\mathrm{HP}^{\circ}}^{\circ}=-385 \mathrm{~kJ} \mathrm{~mol}^{-1}$ (considering equation 4), which suggests that $1,3-\mathrm{PDO}$ oxidation is very favourable.

$$
\underset{1,3-P D O}{\mathrm{C}_{3} \mathrm{H}_{8} \mathrm{O}_{2}}+2 \mathrm{PQQ}+\mathrm{H}_{2} \mathrm{O} \rightarrow \underset{3-H P}{\mathrm{C}_{3} \mathrm{H}_{5} \mathrm{O}_{3}^{-}}+\mathrm{H}^{+}+2 \mathrm{PQQH}_{2}
$$

\subsubsection{3-hydroxypropionitrile hydrolysis}

Some bacterial genera, such as Rhodococcus and Comamonas, are able to hydrolyse aliphatic nitriles into corresponding carboxylic acids, in particular 3-hydroxypropionitrile (3-HPN) to 3-HP. The conversion can be carried out in one step using a nitrilase or in two steps by a combination of a nitrile hydratase and an amidase (Fig. 2.F). In the latter case, 3-HPN is first dehydrated by the nitrile hydratase to 3-hydroxypropionamide (3-HPAm), which is subsequently converted into 3-HP by the amidase (Bramucci et al., 2002; Hann et al., 2003). A nitrile-hydrolyzing activity was recently reported for the first time for the Meyerozyma genus. A yeast strain, identified as Meyerozyma guilliermondii, was isolated from soil and was found to be able to convert 3-HPN to 3-HP (Zhang et al., 2017). As highlighted by 
Bramucci et al., carboxylic acids are readily obtained from nitriles through various chemical processes, however these chemical processes require strong acid or base use, or high operating temperatures. Therefore, using a biocatalyst instead should allow a greener and less energetically costly process. This biological pathway has several advantages: (i) its selectivity, 3-HP was each time the only reported product during 3-HPN bioconversion (Bramucci et al., 2002; Hann et al., 2003; Zhang et al., 2017), (ii) the fact that no cofactor is required. However, 3-HPN may not be as readily available as other substrates, such as glycerol or glucose. It should also be noted that the overall reaction (see equation 5) has a slightly positive standard free energy $\Delta \mathrm{rG}_{3-\mathrm{HPN} \rightarrow 3-\mathrm{HP}}^{\circ \prime}=8 \mathrm{~kJ} \mathrm{~mol}^{-1}$, thus indicating that operating conditions of the process have to be carefully chosen, in order to avoid thermodynamic hurdles.

$$
\underset{3-H P N}{\mathrm{C}_{3} \mathrm{H}_{5} \mathrm{ON}}+2 \mathrm{H}_{2} \mathrm{O} \rightarrow \underset{3-H P}{\mathrm{C}_{3} \mathrm{H}_{5} \mathrm{O}_{3}^{-}}+\mathrm{NH}_{4}^{+}
$$

\subsubsection{Autotrophic $\mathrm{CO}_{2}$ assimilation through the 3-hydroxypropionate/4-} hydroxybutyrate cycle and the 3-hydroxypropionate bi-cycle

3-HP is also involved in carbon dioxide-assimilating metabolic pathways. There are six different $\mathrm{CO}_{2}$ fixing pathways, as reviewed by Saini et al. and by Fuchs (Fuchs, 2011; Saini et al., 2011). Two of these pathways involve 3-HP as a key intermediary product: the 3hydroxypropionate/4-hydroxybutyrate cycle and the 3-hydroxypropionate bi-cycle. The latter was discovered almost 30 years ago, while the former was discovered ten years ago (Berg et al., 2007; Holo, 1989). Producing 3-HP from carbon dioxide would be very interesting, because it is a cheap, abundant and environmentally relevant carbon source. This would constitute the main advantage of using this kind of pathway. However, 3-HP is not an end product of these pathways and it is not naturally accumulated, or if so only in small amounts (Holo, 1989). Genetic engineering is therefore required in order to take advantage of these metabolic routes. In fact, research aiming at 3-HP production from $\mathrm{CO}_{2}$ has already been undertaken, but is still at its early stages (Keller et al., 2013; Lian et al., 2016). In these studies, part of the 3-hydroxypropionate/4-hydroxybutyrate cycle from the archeon Metallosphaera sedula was introduced into the archaeon Pyroccocus furiosus. Hence, 3-HP formation was achieved from carbon dioxide as carbon source, dihydrogen as electron donor and maltose as acetyl-CoA and ATP source. At best, the final 3-HP titre reached a few 
hundreds of milligrams per litre (Table 1). Enzymes involved in these autotrophic pathways can also be used for the creation of synthetic heterotrophic pathways. In particular, the malonyl-CoA reductase from the 3-hydroxypropionate bi-cycle of Chloroflexus aurantiacus is used for 3-HP production by recombinant Escherichia coli or Saccharomyces cerevisiae from glucose through the malonyl-CoA route (C. Liu et al., 2016) (see part 2.1.3).

As mentioned above, inorganic carbon fixation into 3-HP was also attempted photosynthetically, using engineered cyanobacteria Synechocystis sp. PCC 6803 or Synechoccus elongatus PCC 7942 (Lan et al., 2015; Wang et al., 2016b; Y. Wang et al., 2015). $\mathrm{CO}_{2}$ was assimilated into pyruvate or phosphoenolpyruvate through the ubiquitous Calvin cycle. These intermediates were then further reduced into 3-HP either through the malonyl-CoA pathway (Lan et al., 2015; Wang et al., 2016b) or through the $\beta$-alanine pathway (Lan et al., 2015).

\subsubsection{Other pathways}

Another metabolic route, the propionyl-CoA pathway, was recently explored for 3-HP production from propionate in E. coli (Luo et al., 2016). Propionate is first converted to propionyl-CoA, which is subsequently oxidised into acryloyl-CoA using an equivalent of $\mathrm{NADP}^{+}$. Acryloyl-CoA is then hydrated to 3-HP-CoA, whose CoA residue is then transferred to acetate, thus leading to the production of one equivalent of 3-HP and acetyl-CoA. A maximum of $1.60 \mathrm{~g} \mathrm{~L}^{-1}$ was obtained in shake flasks experiments (Luo et al., 2016). Interestingly, it was observed in the same study that in the absence of glucose, 3-HP production was low $\left(0.06 \mathrm{~g} \mathrm{~L}^{-1}\right)$. Indeed, when propionate serves as sole energy and carbon source for bacterial growth, the flow through the propionyl-CoA pathway decreases. It was also suggested that the quantity of ATP produced from propionate, which is not a preferential energy source for E. coli, could not ensure the synthesis of both growth-related and heterologous proteins. 3-HP production was therefore further limited. Glucose addition could help compensate for this energy deficiency (Luo et al., 2016).

Lastly, 3-HP was also found to be an end product of uracil or acrylic acid degradation. This was reported for both prokaryotes and eukaryotes: Escherichia coli K-12 and Saccharomyces kluyveri were shown to produce 3-HP from uracil (Andersen et al., 2008; Loh et al., 2006); and 3-HP production starting from acrylic acid was observed for fungi (Dave et al., 1996; 
Takamizawa et al., 1993) and for bacterium Alcaligenes faecalis (Ansede et al., 1999). It was also reported that 3-HP can be produced - through an unknown pathway - by endophytic fungi as a nematicidal agent (Schwarz et al., 2004). However, except for acrylic acid degradation by Rhodococcus erythropolis (Lee et al., 2009), these various pathways were not evaluated as such for 3-HP commercial production.

Table 1 - Best 3-HP microbial production performances listed by type of metabolic pathway

\begin{tabular}{|c|c|c|c|c|c|c|}
\hline Organism & $\begin{array}{l}\text { Carbon } \\
\text { source }\end{array}$ & Operational technique & Titre & $\begin{array}{l}\text { Overall } \\
\text { process } \\
\text { productivity }\end{array}$ & Yield & Ref \\
\hline \multicolumn{7}{|c|}{ Glycerol oxidation through a CoA-dependent pathway } \\
\hline $\begin{array}{l}\text { Lactobacillus } \\
\text { reuteri }\end{array}$ & glycerol & Fed-batch, 3 L bioreactor & $14 \mathrm{~g} \mathrm{~L}^{-1}$ & $0.25 \mathrm{~g} \mathrm{~L}^{-1} \mathrm{~h}^{-1 \mathrm{~b}}$ & $\begin{array}{l}0.49 \mathrm{~mol}_{\mathrm{C}} \\
\mathrm{mol}_{\mathrm{C}}^{-1 \mathrm{~b}}\end{array}$ & $\begin{array}{l}\text { (Dishi } \\
\text { sha et } \\
\text { al., } \\
2015 \text { ) }\end{array}$ \\
\hline \multicolumn{7}{|c|}{ Glycerol oxidation through a CoA-independent pathway } \\
\hline Escherichia coli $^{\text {a }}$ & $\begin{array}{l}\text { glycerol } \\
+ \text { glucose }\end{array}$ & $\begin{array}{l}\text { Fed-batch, } 5 \mathrm{~L} \\
\text { bioreactor, vitamin } \mathrm{B}_{12} \\
\text { addition, IPTG induction }\end{array}$ & $71.9 \mathrm{~g} \mathrm{~L}^{-1}$ & $1.8 \mathrm{~g} \mathrm{~L}^{-1} \mathrm{~h}^{-1}$ & - & $\begin{array}{l}\text { (Chu } \\
\text { et al., } \\
2015)\end{array}$ \\
\hline $\begin{array}{l}\text { Klebsiella } \\
\text { pneumoniae }^{\text {a }}\end{array}$ & glycerol & $\begin{array}{l}\text { Fed-batch, } 5 \mathrm{~L} \\
\text { bioreactor, IPTG } \\
\text { induction }\end{array}$ & $83.8 \mathrm{~g} \mathrm{~L}^{-1}$ & $1.16 \mathrm{~g} \mathrm{~L}^{-1} \mathrm{~h}^{-1 \mathrm{~b}}$ & $\begin{array}{l}0.60 \mathrm{~mol}_{\mathrm{C}} \\
\mathrm{mol}_{\mathrm{C}}^{-1 \mathrm{~b}}\end{array}$ & $\begin{array}{l}\text { (Y. Li } \\
\text { et al., } \\
\text { 2016) }\end{array}$ \\
\hline $\begin{array}{l}\text { Corynebacterium } \\
\text { glutamicum a }^{\text {a }}\end{array}$ & $\begin{array}{l}\text { xylose }+ \\
\text { glucose }\end{array}$ & $\begin{array}{l}\text { Fed-batch, } 5 \mathrm{~L} \\
\text { bioreactor, vitamin } \mathrm{B}_{12} \\
\text { addition, IPTG induction }\end{array}$ & $54.8 \mathrm{~g} \mathrm{~L}^{-1}$ & $0.76 \mathrm{~g} \mathrm{~L}^{-1} \mathrm{~h}^{-1 \mathrm{~b}}$ & - & $\begin{array}{l}\text { (Z. } \\
\text { Chen } \\
\text { et al., } \\
\text { 2017) }\end{array}$ \\
\hline $\begin{array}{l}\text { Corynebacterium } \\
\text { glutamicum a }^{\text {a }}\end{array}$ & glucose & $\begin{array}{l}\text { Fed-batch, } 5 \mathrm{~L} \\
\text { bioreactor, vitamin B12 } \\
\text { addition, IPTG induction }\end{array}$ & $62.6 \mathrm{~g} \mathrm{~L}^{-1}$ & $0.87 \mathrm{~g} \mathrm{~L}^{-1} \mathrm{~h}^{-1 \mathrm{~b}}$ & $\begin{array}{l}0.51 \mathrm{~mol}_{\mathrm{C}} \\
\mathrm{mol}_{\mathrm{C}}^{-1}\end{array}$ & $\begin{array}{l}\text { (Z. } \\
\text { Chen } \\
\text { et al., } \\
\text { 2017) }\end{array}$ \\
\hline \multicolumn{7}{|c|}{ Malonyl-CoA pathway } \\
\hline Escherichia coli $^{\text {a }}$ & glucose & $\begin{array}{l}\text { Fed-batch, } 1.8 \mathrm{~L} \\
\text { bioreactor, IPTG } \\
\text { induction }\end{array}$ & $48.4 \mathrm{~g} \mathrm{~L}^{-1}$ & - & $\begin{array}{l}0.53 \mathrm{~mol}_{\mathrm{C}} \\
\mathrm{mol}_{\mathrm{C}}^{-1}\end{array}$ & $\begin{array}{l}\text { (Lync } \\
\text { h et } \\
\text { al., } \\
2011 \text { ) }\end{array}$ \\
\hline Escherichia coli $^{\text {a }}$ & glucose & $\begin{array}{l}\text { Fed-batch, } 5 \text { L } \\
\text { bioreactor, IPTG }\end{array}$ & $40.6 \mathrm{~g} \mathrm{~L}^{-1}$ & $0.56 \mathrm{~g} \mathrm{~L}^{-1} \mathrm{~h}^{-1 \mathrm{~b}}$ & $\begin{array}{l}0.19 \mathrm{~mol}_{\mathrm{C}} \\
\mathrm{mol}_{\mathrm{C}}{ }^{-1}\end{array}$ & $\begin{array}{l}\text { (C. } \\
\text { Liu et }\end{array}$ \\
\hline
\end{tabular}




\begin{tabular}{|c|c|c|c|c|c|c|}
\hline & & induction & & & & $\begin{array}{l}\text { al., } \\
\text { 2016) }\end{array}$ \\
\hline \multicolumn{7}{|c|}{$\beta$-Alanine pathway } \\
\hline Escherichia coli $^{\text {a }}$ & glucose & $\begin{array}{l}\text { Fed-batch, } 6.6 \mathrm{~L} \\
\text { bioreactor }\end{array}$ & $31.1 \mathrm{~g} \mathrm{~L}^{-1}$ & $0.63 \mathrm{~g} \mathrm{~L}^{-1} \mathrm{~h}^{-1 \mathrm{~b}}$ & $\begin{array}{l}0.423 \mathrm{~mol}_{\mathrm{C}} \\
\mathrm{mol}_{\mathrm{C}}^{-1}\end{array}$ & $\begin{array}{l}\text { (Song } \\
\text { et al., } \\
2016 \text { ) }\end{array}$ \\
\hline $\begin{array}{l}\text { Issatechenkia } \\
\text { orientalis }^{\mathrm{a}}\end{array}$ & glucose & Fed-batch, 3 L bioreactor & $22.8 \mathrm{~g} \mathrm{~L}^{-1}$ & $0.50 \mathrm{~g} \mathrm{~L}^{-1} \mathrm{~h}^{-1} \mathrm{~b}$ & - & $\begin{array}{l}\text { (Barn } \\
\text { hart et } \\
\text { al., } \\
2015)\end{array}$ \\
\hline $\begin{array}{l}\text { Saccharomyces } \\
\text { cerevisiae }^{\text {a }}\end{array}$ & glucose & Fed-batch, 1 L bioreactor & $13.7 \mathrm{~g} \mathrm{~L}^{-1}$ & $0.17 \mathrm{~g} \mathrm{~L}^{-1} \mathrm{~h}^{-1}$ & $\begin{array}{l}0.14 \text { mol}_{\mathrm{C}} \\
\operatorname{mol}_{\mathrm{C}}^{-1}\end{array}$ & $\begin{array}{l}\text { (Boro } \\
\text { dina } \\
\text { et al., } \\
2015 \text { ) }\end{array}$ \\
\hline \multicolumn{7}{|c|}{ Other heterotrophic routes } \\
\hline $\begin{array}{l}\text { Gluconobacter } \\
\text { oxydans }\end{array}$ & 1,3-PDO & Batch, 7 L bioreactor & $60.5 \mathrm{~g} \mathrm{~L}^{-1}$ & $2.52 \mathrm{~g} \mathrm{~L}^{-1} \mathrm{~h}^{-1} \mathrm{~b}$ & $\begin{array}{l}0.94 \mathrm{~mol}_{\mathrm{C}} \\
\mathrm{mol}_{\mathrm{C}}^{-1}\end{array}$ & $\begin{array}{l}\text { (Zhao } \\
\text { et al., } \\
\text { 2015) }\end{array}$ \\
\hline $\begin{array}{l}\text { Comamonas } \\
\text { testosteroni }\end{array}$ & 3-HPN & $\begin{array}{l}\text { Batch, } 50 \mathrm{~mL} \text { jacketed } \\
\text { reaction vessel }\end{array}$ & - & $23 \mathrm{~g} \mathrm{~L}^{-1} \mathrm{~h}^{-1}$ & - & $\begin{array}{l}\text { (Hann } \\
\text { et al., } \\
\text { 2003) }\end{array}$ \\
\hline \multicolumn{7}{|l|}{ Autotrophic routes } \\
\hline $\begin{array}{l}\text { Synecocytis sp. } \\
\text { PCC } 6803^{\text {a }}\end{array}$ & $\mathrm{NaHCO}_{3}$ & $\begin{array}{l}\text { Fed-batch, } 100 \mathrm{~mL} \\
\text { Shake-flask, cupric ion } \\
\text { induction }\end{array}$ & $0.837 \mathrm{~g} \mathrm{~L}^{-1}$ & - & - & $\begin{array}{l}\text { (Wan } \\
\text { g et } \\
\text { al., } \\
2016 b \\
)\end{array}$ \\
\hline $\begin{array}{l}\text { Pyrococcus } \\
\text { furiosus }^{\text {a }}\end{array}$ & $\mathrm{CO}_{2}$ & $\begin{array}{l}\text { Batch, 1 L bioreactor, } \\
\text { heat activation of the } \\
\text { recombinant enzymatic } \\
\text { pathway }\end{array}$ & $0.366 \mathrm{~g} \mathrm{~L}^{-1}$ & - & - & $\begin{array}{l}\text { (Lian } \\
\text { et al., } \\
2016 \text { ) }\end{array}$ \\
\hline
\end{tabular}

\section{${ }^{\text {a }}$ Engineered microorganisms}

${ }^{\mathrm{b}}$ Value calculated from data given in the article

- Value could not be calculated from given data

\subsection{Optimizing 3-HP production through metabolic engineering}

417 An efficient microbial host is required in order to ensure a commercially relevant process.

418 Therefore, once a metabolic route towards 3-HP is introduced in a non-native producer, 
further metabolic engineering works are needed to obtain an efficient microbial candidate. This is also true for some native producers, such as Lactobacillus reuteri, that do not naturally produce high amounts of 3-HP. Metabolic engineering strategies were already extensively reviewed on several occasions (David et al., 2017; Jiang et al., 2009; Kumar et al., 2013; Kumar and Park, 2017; Liu et al., 2017; Matsakas et al., 2014). The key points to understanding the main challenges are presented here along with the most recent works.

In order to improve 3-HP yields, it is necessary that the carbon flux from the substrate is sufficiently channelled through the 3-HP producing pathway. Efforts have thus been made in order to reduce the carbon flow in competitive pathways, which mainly include biomass build-up and efficient ATP-generating pathways. Lactate and acetate are major by-products during 3-HP production from glycerol or from sugars. Final titre of lactate was successfully reduced by Chen et al. by knocking out the $I h A$ gene encoding a lactate dehydrogenase in Corynebacterium glutamicum. In shake-flask cultivation, the resulting strain produced almost no lactate $\left(0.4 \mathrm{~g} \mathrm{~L}^{-1}\right.$ versus $7.4 \mathrm{~g} \mathrm{~L}^{-1}$ with the control strain) and had an increase of $19.4 \%$ in 3-HP production from glucose (Z. Chen et al., 2017). Knockouts of genes encoding enzymes involved in the production of acetate was also proven efficient during 3-HP production through the CoA-independent glycerol pathway in C. glutamicum and E. coli by Chen et al. and Jung et al., respectively. A decrease of $52.8 \%$ and $97.2 \%$ in acetate production were observed in C. glutamicum and E. coli respectively, while 3-HP production was improved by $25.9 \%$ and $27.3 \%$ respectively (Z. Chen et al., 2017; Jung et al., 2014). Such knockouts had however no significant impact on lactate and acetate production by K. pneumoniae. This was attributed to the existence of other lactate- or acetate-producing pathways that were not knocked-out (Y. Li et al., 2016). In the case of acetate, other approaches were also undertaken, such as down-regulating the assimilatory metabolism of glycerol (Kim et al., 2014; Ko et al., 2017; Tokuyama et al., 2014), or deleting a gene encoding a TCA cycle repressor (ArcA), so that acetate overflow is prevented (M. Liu et al., 2016). When considering 3-HP production through the malonyl-CoA pathway, an important issue to address is the competition with the fatty acid biosynthesis pathway (see part 2.1.3). Attenuating the latter pathway leads to higher intracellular levels of malonyl-CoA, thus improving 3-HP production. The fatty acid synthesis was primarily inhibited by using cerulenin (Li et al., 2015; Lynch et al., 2011; Rogers and Church, 2016; Ye et al., 2016). Due to the cost of adding such an inhibitor to a fermentation broth, alternative approaches were proposed through genetic engineering (X. Chen et al., 2017; Lynch et al., 2011; Ye et al., 
2016). Although the disruption of genes involved in central metabolism can improve the 3-HP yield, it was also observed that it can hinder cell growth (Ko et al., 2017; Y. Li et al., 2016; Lynch et al., 2011; Tokuyama et al., 2014). A novel approach was recently proposed by Tsuruno et al. They developed a metabolic toggle switch in order to perform conditional repression of genes related to central glycerol metabolism, so that 3-HP is produced while avoiding growth defect (Tsuruno et al., 2015). Another promising strategy was proposed by David et al., who achieved a dynamic control of the malonyl-CoA node in S. cerevisiae. The expression of a fatty acid synthase was subjected to control by a glucose-sensitive promoter. Hence, fatty acid biosynthesis was down-regulated in glucose-limited conditions only. This can ensure that sufficient biomass is produced, before the carbon flux is channelled towards 3HP synthesis (David et al., 2016).

Another major aspect of pathway optimisation is the balancing of the different steps within the 3-HP producing pathway. Imbalanced pathways can lead to the accumulation of metabolic intermediates, thus hindering the process performances. This is particularly true when 3-HP is produced from glycerol: imbalance between the high glycerol dehydratase activity and the low aldehyde dehydrogenase activity results in detrimental accumulation of the toxic intermediate 3-HPA (see parts 2.1.1 and 2.1.2). Until now, this issue was mainly addressed by varying the strength of the promoters, or by varying the number of gene copies on the plasmids. A novel technique was recently applied by Lim et al. They used the forward engineering "UTR Designer" software in order to optimise the glycerol dehydratase activity. This software helps predict the translation initiation efficiency of a mRNA sequence, given the 5'-untranslated region (5'-UTR) located upstream. Using this software, Lim et al. designed 5'-UTRs with different strength, and showed that the glycerol dehydratase activity was dependent on the 5'-UTR used. Their study resulted in a well-balanced pathway in E. coli and a maximum titre of $40.51 \mathrm{~g} \mathrm{~L}^{-1}$ was reached (productivity: $1.35 \mathrm{~g} \mathrm{~L}^{-1} \mathrm{~h}^{-1}$; yield: $0.99 \mathrm{~mol}_{3}$ HP molglycerol) (Lim et al., 2016). Pathway balancing was also achieved in E. coli by using a bicistronic synthetic cassette architecture. No 3-HPA accumulation was measured when the aldehyde dehydrogenase activity was 8 -fold higher than the glycerol dehydratase activity (Sankaranarayanan et al., 2017). As mentioned in section 2.1.3, an imbalance also exists between the two functional sites of the malonyl-CoA reductase (MCR) in the malonyl-CoA pathway. Balance between them was achieved by Liu et al. by improving the MCR-C fragment by directed evolution and by decreasing the MCR-N activity (C. Liu et al., 2016). 
Redox cofactors regeneration is a major issue for metabolic pathways optimisation. Indeed, 3HP generating pathways generally involve at least one redox equilibrium (Fig. 2). For instance, when 3-HP is produced from glycerol, 3-HPA is oxidised to 3-HP using $\mathrm{NAD}^{+}$as electron acceptor. $\mathrm{NAD}^{+}$regeneration is maximal in aerobic conditions, when the electron transport chain is active and electrons are accepted by oxygen. However, aerobic conditions are incompatible with efficient vitamin $\mathrm{B}_{12}$ synthesis (see part 2.3). $\mathrm{NAD}^{+}$regeneration has typically been ensured by using a NADH oxidase (Li et al., 2013). An alternative strategy was suggested by Li et al., which consists in using a NAD ${ }^{+}$-independent aldehyde dehydrogenase from Pseudomonas sp. AIU 362 (Li et al., 2013). This enzyme uses $\mathrm{O}_{2}$ as electron acceptor, so this strategy does not fully resolve the contradiction with anaerobic vitamin $\mathrm{B}_{12}$ synthesis. In the malonyl-CoA pathway, the reduction of malonyl-CoA to 3-HP necessitates that two electron equivalents are provided by NADPH. Meanwhile, the upstream part of the pathway consists in the oxidation of glucose to pyruvate, thus generating reducing equivalents (Fig. 2.C). Chen et al. took advantage of this by engineering S. cerevisiae, so that the reducing equivalents generated by the upstream steps of the pathway could be generated as NADPH, instead of NADH, thus ensuring the NADPH supply of the last steps of the pathway (Chen et al., 2014).

Furthermore, cells' transporting functions were shown to have significant impact on 3-HP production. 3-HP production was successfully increased by $8 \%$ in C. glutamicum when the native glucose uptake system was replaced by a route involving inositol permeases and glucokinase. By doing so, glucose uptake was no longer subjected to the need for phosphoenolpyruvate (Z. Chen et al., 2017). In Synechocystis sp. PCC6803, proteomic and metabolomic approaches led to the identification of 11 genes potentially relevant for 3-HP synthesis. Interestingly, five of them were related to transport functions in cells. Results showed that overexpressing genes putatively involved in cobalt/nickel, manganese and phosphate transports could improve 3-HP production (Wang et al., 2016a).

Lastly, a major concern when designing a bioprocess is the genetic stability of the constructed microbial agent. Genetic engineering in bacteria is mainly achieved using plasmids as vectors because for many species, efficient methods to transfer a plasmid into a cell are known. Yet, they are subjected to major instabilities, such as structural and segregational instabilities (Wang and Tian, 2017). Attempt has thus been made at developing a plasmid-free host for 3HP production. The proof of concept was provided by Wang and Tian who engineered a 
521 plasmid-free, 3-HP-producing strain of K. pneumoniae through homologous recombination

522 (Wang and Tian, 2017).

523

\subsection{Microbial agents for 3-HP production}

525

As illustrated in the previous part, a variety of both microbial species and carbon sources are being investigated for the purpose of 3-HP production. Figure 3 sums up the different microorganisms/substrates couples already implemented. Classical microbial chassis are interesting candidates because they are well-known and well-characterised. They are generally easy-to-use fast growing organisms. A lot of tools are already available for their metabolic engineering as well as for their scaling-up. In particular, E. coli is one of the most widely used microorganisms for 3-HP production so far. Bacillus subtilis and Corynebacterium glutamicum are further bacterial model organisms for industrial applications (Becker and Wittmann, 2012; Zhang and Zhang, 2010). As reviewed by Zhang and Zhang, 2010, B. subtilis displays interesting advantages such as the Generally Recognised As Safe (GRAS) status, fast growth, low nutrient requirements, and great tolerance to salts and solvents. In addition, the biomass of $B$. subtilis thus produced may be further utilised as a feed additive (Rychen et al., 2017). Those features are particularly relevant in the case of 3-HP production. Indeed, it is only a low-value added bioproduct so the process needs to be as costeffective as possible in order for it to be economically viable. What is more, B. subtilis is able to naturally uptake a variety of sugars, including xylose. Xylose is an interesting substrate because it is one of the sugars that can be obtained from lignocellulosic feedstocks. Until now, 3-HP production from xylose was considered in E. coli, C. glutamicum and S. cerevisiae (Z. Chen et al., 2017; Jung et al., 2015; Kildegaard et al., 2015), but B. subtilis may also be a good candidate for second-generation (i.e. using non-food feedstocks) 3-HP production.

From an industrial point of view, yeasts are often preferred over bacteria due to their higher tolerance to low $\mathrm{pH}$ values, both facilitating the downstream processes and lowering the overall cost. In addition, S. cerevisiae also has the GRAS status (Fig. 3). Only a few studies have yet focused on yeasts in comparison to E. coli. Several methods for 3-HP production from glucose in recombinant yeasts were patented in recent years by Novozymes and SK Innovation (Barnhart et al., 2015; Bindel, 2014; Park et al., 2016). Interestingly, some yeast species were chosen over S. cerevisiae for their greater tolerance to 3-HP (Barnhart et al., 2015; Suyama et al., 2017). They notably include Issatechenkia orientalis, which currently 
holds the record 3-HP titre in yeast, which is $22.8 \mathrm{~g} \mathrm{~L}^{-1}$ (Table 1). Recombinant I. orientalis expressed an aspartate 1-decarboxylase from the insect Aedes aegypti, and was implemented in a 3L-bioreactor with a glucose feed (Barnhart et al., 2015). However, as explained by the authors of this patent, an important drawback of using yeasts is that their metabolic engineering is typically more complicated than for bacteria. This is notably due to the compartmentalisation of eukaryotic cells. This requires that special attention be paid to targeting signals and also to the transportation of intermediates from one cell compartment to another (Barnhart et al., 2015). Nevertheless, efficient tools exist for engineering $S$. cerevisiae. For instance, a toolkit was developed for marker-less integration of genes into $S$. cerevisiae using CRISPR-Cas9 (Clustered Regularly Interspaced Short Palindromic Repeats (CRISPR) and CRISPR-associated endonuclease (Cas9)). This toolkit was used for 3-HP production by enhancing the malonyl-CoA pathway through three different strategies. The most successful strategy consisted in overexpressing a pyruvate dehydrogenase complex and could increase the 3 -HP titre by $+23 \%$ when using the industrial strain Ethanol Red (JessopFabre et al., 2016).

When considering 3-HP production from glycerol a major limitation of using an industrial chassis is that they generally cannot produce vitamin $\mathrm{B}_{12}$ on their own. As explained above, vitamin $\mathrm{B}_{12}$ is a necessary cofactor for glycerol's conversion to 3-HPA, both through the CoA-dependent pathway of Lactobacilli sp. and through the CoA-independent pathway of $K$. pneumoniae (see parts 2.1.1 and 2.1.2). Therefore, when microbial chassis such as E. coli, B. subtilis or C. glutamicum are transformed with a glycerol dehydratase from K. pneumoniae, costly addition of vitamin $B_{12}$ to the culture medium is required (Table 1). Using the vitamin B12-independent glycerol dehydratase from Clostridium butyricum (O’Brien et al., 2004) could be a way to work around this issue. Another possibility is to use the native species: Lactobacillus reuteri and K. pneumoniae are indeed prototroph for vitamin $\mathrm{B}_{12}$, so there is no need to supply it to the medium. These species also have further advantages. L. reuteri notably has the GRAS status and was even proven to be a probiotic agent (Casas and Dobrogosz, 2000). As for it, K. pneumoniae was the most studied organism for 3-HP production so far and offers the following advantages: (i) glycerol fermentation pathways have been studied extensively: present knowledge of glycerol metabolism in K. pneumoniae was recently and extensively reviewed (Kumar and Park, 2017); (ii) it can grow directly on glycerol, so the fermentative process could come down to a single step; (iii) K. pneumoniae can grow on glycerol both anaerobically and aerobically; and (iv) it has a great glycerol 
assimilation rate. However, K. pneumoniae is pathogenic to humans (Podschun and Ullmann, 1998), making a process based on this species unlikely to reach industrial scale. Yet, a new isolate Klebsiella sp. AA405 carrying low levels of virulence factors was recently identified as potential host for 3-HP production (Li et al., 2017). Furthermore, an important limitation to efficient 3-HP production remains: there exists a contradiction between vitamin $\mathrm{B}_{12}$ synthesis and $\mathrm{NAD}^{+}$regeneration. Indeed, maximum $\mathrm{NAD}^{+}$regeneration is reached under aerobic conditions, while maximum vitamin $\mathrm{B}_{12}$ synthesis is achieved anaerobically. Using the vitamin $\mathrm{B}_{12}$-independent glycerol dehydratase from $C$. butyricum would be subjected to the same limitation, since it is active only in strictly anaerobic conditions (O'Brien et al., 2004). Zhou et al. proposed an alternative solution by using Pseudomonas denitrificans. The strain is able to produce vitamin $\mathrm{B}_{12}$ aerobically, and was transformed with glycerol dehydratase and aldehyde dehydrogenase genes from K. pneumoniae (Zhou et al., 2013). A maximum titre of $4.92 \mathrm{~g} \mathrm{~L}^{-1}$ was reached, corresponding to a $0.67 \mathrm{~mol}_{3-\mathrm{HP}} \mathrm{mol}^{-1}$ glycerol yield.

Until now, 3-HP production is primarily achieved from glycerol or glucose, which are both relatively cheap and abundant carbon sources. Glycerol is notably a relevant substrate for biorefinery processes: it is a by-product of first-generation biodiesel production. A large glycerol surplus has been formed, making it a cheap and abundant carbon source (Chen and Liu, 2016). An even cheaper and more abundantly available carbon source would be atmospheric $\mathrm{CO}_{2}$. 3-HP production was already achieved using inorganic carbon. The proof of concept was provided through an original approaches in archea Pyrococcus furiosus and Metallosphaera sedula (Keller et al., 2013; Lian et al., 2016), as well as in cyanobacteria Synechocystis elongatus and Synechocystis sp. PCC 6803 (Lan et al., 2015; Wang et al., 2016b; Y. Wang et al., 2015) (see part 2.1.7). In contrast, genetic engineering tools are limited for these species as compared to those available for usual microbial chassis. However, cyanobacteria and Synechocystis sp. in particular were recently identified as potential next generation chassis for synthetic biology (Adams, 2016; Branco dos Santos et al., 2014). 3-HP production could therefore benefit from the development of new toolkits for these species, such as CRISPR-Cas systems. Interestingly, a process was recently patented by Verdant Bioproducts Limited for 3-hydroxypropionamide (3-HPAm) production from atmospheric $\mathrm{CO}_{2}$ and nitrogen, using Acetobacter lovaniensis (Finnegan, 2017). The patent only mentions the possibility of subsequently converting 3-HPAm to 3-HP through a chemical process. However, a two-step bioprocess could be envisaged: $\mathrm{CO}_{2}$ and nitrogen are first assimilated by A. lovaniensis into 3-HPAm, which is then converted to 3-HP by amidases from Comamonas 
testosteroni, for instance.

Lastly, the combined use of two complementary microorganisms was recently investigated for 3-HP production from glycerol (Dishisha et al., 2015; Sabet-Azad et al., 2015; Zhao et al., 2015) (see part 3.2). In particular, acetic acid bacteria were used to oxidise the 1,3-PDO produced either by K. pneumoniae or L. reuteri into 3-HP. One great advantage of using acetic acid bacteria is their ability to resist organic acids, and grow under acidic conditions (Raspor and Goranovič, 2008; B. Wang et al., 2015). Furthermore, acetic acid bacteria have long been used in the food industry for vinegar production, so they should be suited well for industrial scale-up.

\section{Overcoming hurdles to 3-HP commercial production through process engineering}

\subsection{Operational strategies for 3-HP-producing fermentative processes}

\subsubsection{Fermentation mode}

To this day, 3-HP production is primarily achieved through bench-scale, fed-batch fermentations. Almost all studies reviewed for this paper that carried out 3-HP production in bioreactors used smaller ones (from $1 \mathrm{~L}$ to $7 \mathrm{~L}$, see below for exceptions) and most of them were operated under fed-batch mode. An important part of the research effort being focused on genetic engineering, fed-batch fermentations in bioreactors are essentially undertaken in order to confirm a novel strain's potential as a 3-HP producer. During a fed-batch, the medium is gradually supplied with substrate, as cell population grows and products accumulate, which allows higher cell densities and product titres, in comparison with batch mode. Fed-batch cultures are advantageous for the production of both growth-associated and non growth-associated metabolites (Liu, 2017). In the former case, a continuous exponential substrate supply can control the microbial growth rate in order to make the exponential phase last longer, thus maximizing the metabolite production (Liu, 2017). This kind of approach, however, requires an in-depth understanding of the strain's physiological needs and does not yet appear to have been applied to 3-HP biosynthesis.

An important feature of fed-batch techniques is that the substrate concentration is kept low throughout the fermentation. This helps limit deleterious phenomena due to high substrate 
concentrations or due to detrimental intermediates accumulation. Glycerol concentration is typically kept around a relatively low set value, ranging from $5 \mathrm{~g} \mathrm{~L}^{-1}$ to $25 \mathrm{~g} \mathrm{~L}^{-1}$ (Huang et al., 2013; Y. Li et al., 2016; Zhao et al., 2015). Indeed, it was previously reported that glycerol concentrations above $40 \mathrm{~g} \mathrm{~L}^{-1}$ had detrimental effects on the growth of K. pneumoniae. Maximal tolerated concentrations were estimated at $110 \mathrm{~g} \mathrm{~L}^{-1}$ and $133 \mathrm{~g} \mathrm{~L}^{-1}$ for aerobic and anaerobic cultures respectively (Cheng et al., 2005). This rules out the possibility of efficient batch strategies for 3-HP production at high titres from glycerol. Moreover, in conjunction with genetic engineering strategies, fed-batch mode also offers a way to control levels of undesired side products in the final broth. During aerobic cultures, fast-growing cells use fermentation instead of the more energy efficient respiratory chain (Basan et al., 2015). This ubiquitous phenomenon is generally referred to as the overflow metabolism. Part of the carbon flux is then diverted from the tricarboxylic acid (TCA) cycle to incompletely oxidised end-products, such as acetate in the case of E. coli or ethanol in the case of S. cerevisiae. Not only does the production of these metabolites hinder 3-HP yields, but it also has toxic effects on cells. This issue was acknowledged several times during 3-HP production (Kildegaard et al., 2016; M. Liu et al., 2016; Raj et al., 2009; Sankaranarayanan et al., 2014) and was addressed through both fed-batch (Kildegaard et al., 2016) and genetic engineering (M. Liu et al., 2016) strategies. As for wild type Lactobacillus reuteri, since it cannot grow on glycerol as sole carbon or energy source, no overflow phenomenon is involved. However, it was demonstrated by Dishisha et al. that glycerol dehydration to 3-HPA by resting $L$. reuteri cells is at least 10 times faster than 3-HPA consumption, leading to detrimental 3-HPA accumulation in batch mode (Dishisha et al., 2014). A specific glycerol consumption rate ( $\mathrm{q}_{\mathrm{Gly}}$ ) of $128.3 \mathrm{mg}$ glycerol per grams of cell dry weight (cdw) was hence identified as maximum value in order to produce only 1,3-PDO and 3-HP from glycerol, without any 3-HPA accumulation. This allowed Dishisha et al. to design a fed-batch bioconversion using wild type L. reuteri as a biocatalyst that did not produce 3-HPA: the glycerol feed was maintained at 0.75 gglycerol $^{-1}$, which is half the maximum rate given the dry weight of biocatalyst used in the experiment. This process achieved a $14 \mathrm{~g} \mathrm{~L}^{-1} 3$-HP titre with a $0.25 \mathrm{~g} \mathrm{~L}^{-1} \mathrm{~h}^{-1}$ productivity (Dishisha et al., 2015). This illustrates how process design can be guided by the understanding of the microbial metabolism and how it can help overcome hurdles related to enzymatic kinetics. As pointed out by Li et al., in K. pneumoniae too, the aldehyde dehydrogenase is the velocity-limiting enzyme for glycerol conversion to 3-HP (Y. Li et al., 2016). So, similarly to the work of Dishisha et al., fed-batch strategies should allow better 3-HP production using $K$. pneumoniae. 
692 The contradiction between anaerobic vitamin $\mathrm{B}_{12}$ regeneration and aerobic $\mathrm{NAD}^{+}$regeneration

693

694

695

696

697

698

699

700

701

702

703

704

705

706

707

708

709

710

711

712

713

714

715

716

717

718

719

720

721

722

723

724 during glycerol conversion to 3-HP (see part 2.3) was recently addressed through electrofermentation for the first time (Kim et al., 2017). Electro-fermentation is still an emerging technology and was defined in 2016 as a fermentative process in which polarised electrodes are added and can be used both as a driving tool and for fine redox control (Moscoviz et al., 2016a; Schievano et al., 2016). Electro-fermentation relies on the ability some microorganisms have to exchange electrons with solid electrodes, either directly or through redox shuttles. In the case of anodic electro-fermentation, electrons are transferred from microorganisms to the anode. In their study, Kim et al. grew a recombinant K. pneumoniae overexpressing aldehyde dehydrogenase in the anodic compartment of a bioelectrochemical bioreactor. Electrodes were poised at $+0.5 \mathrm{~V}$ vs. $\mathrm{Ag} / \mathrm{AgCl}$ and 2-hydroxy-1,4naphthoquinone (HQN) was added in the medium as an electron shuttle between $K$. pneumoniae and the anode. During anaerobic fermentation, electrons were transferred by the bacteria to the electrode, resulting in current generation in the external circuit and in lower intracellular $\mathrm{NADH} / \mathrm{NAD}^{+}$ratios. The $3-\mathrm{HP}$ to $1,3-\mathrm{PDO}$ ratio thus shifted from 0.84 in fermentative control to 2.26 in electro-fermentative conditions. The process reached a $1.94 \mathrm{~g}$

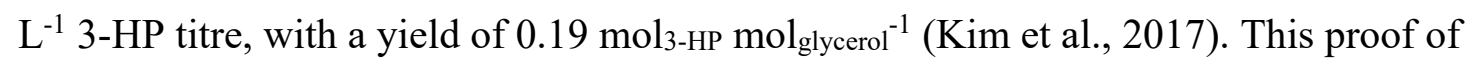
concept demonstrates that $\mathrm{NAD}^{+}$regeneration can be significantly improved in anaerobic conditions: it then becomes possible to achieve both high vitamin $\mathrm{B}_{12}$ and $\mathrm{NAD}^{+}$regeneration. Electro-fermentation gives rise to promising opportunities for overcoming redox limitations of glycerol conversion to 3-HP.

As mentioned at the beginning of this section, 3-HP synthesis is primarily achieved in benchscale bioreactors and to this date, no industrial production of 3-HP is fully implemented. Two notable exceptions can be found in the scientific literature. The archaeon Pyroccocus furiosus that was transformed with part of the 3-HP/4-HB cycle in order to autotrophically produce 3HP was operated in a 20 L bioreactor (Keller et al., 2013). Furthermore, in their 2011 patent, OPX Biotechnologies demonstrated 3-HP production in a $250 \mathrm{~L}$ reactor in fed-batch mode. The E. coli inoculum was prepared in two-steps: $1 \mathrm{~mL}$ of stock culture was first inoculated into a $100 \mathrm{~mL}$ shake-flask, which was subsequently used to inoculate a $14 \mathrm{~L}$ bioreactor. This latter culture was then used to inoculate the $250 \mathrm{~L}$ bioreactor. IPTG was used for the malonylCoA pathway induction. The glucose feed rate was adjusted in order to maintain its concentration between 10 and $15 \mathrm{~g} \mathrm{~L}^{-1}$. In these conditions, a maximal 3-HP titre of $20.7 \mathrm{~g} \mathrm{~L}^{-1}$ 
was reached, with a $0.43 \mathrm{~g} \mathrm{~L}^{-1} \mathrm{~h}^{-1}$ productivity (Lynch et al., 2011).

\subsubsection{Process parameters}

Influence of operating parameters, such as aeration rate and medium composition, on the microbial production of 3-HP were studied. Yet, those aspects have been the object of less intense attention, in comparison to metabolic engineering issues. As previously mentioned, 3HP production from glycerol is an oxidative process; consequently the level of aeration has an impact on final metabolite profile. A first study was conducted by Raj et al. on an E. coli strain expressing the CoA-independent glycerol pathway (Fig. 2.B). By decreasing the liquidto-flask volume ratio from 0.4 to 0.2 to improve the aeration level, 3-HP titer was enhanced by 2.2 -fold ( 0.54 instead of $\left.0.24 \mathrm{mg} \mathrm{L}^{-1}\right)$ while 1,3 -PDO production was slightly reduced (from 0.14 to $0.10 \mathrm{mg} \mathrm{L}^{-1}$ ). However, a 2.5 -fold higher accumulation of acetate and formate was observed under aerobic condition. This was attributed to the changes in aeration conditions and to an undefined metabolic overflow phenomenon (Raj et al., 2009). To understand the response of K. pneumoniae to oxygen supply, Huang et al. measured the transcription levels of genes coding for enzymes of the CoA-independent glycerol oxidation pathway and of the formate hydrogen lyase pathway during aerobic, micro-aerobic, and anaerobic growth in a 5-L bioreactor (Huang et al., 2016). Aeration led to a decrease in the glycerol dehydratase transcription level and to an increase in that of aldehyde dehydrogenase. Simultaneously, hydrogenase- and formate dehydrogenase-encoding genes were upregulated. Authors hypothesized that excess NADH formed by overexpressed aldH is consumed through the pathway comprising these enzymes, while producing dihydrogen. To overcome the issue of $\mathrm{NAD}^{+}$regeneration while preserving glycerol dehydratase activity and vitamin $\mathrm{B}_{12}$ synthesis, Ko et al. worked on aeration conditions during K. pneumoniae growth on glycerol (Ko et al., 2017). After disrupting enzymes of competing pathways (see part 2.2.1), they observed that deletion of the pta-ackA gene responsible for acetate production led to degradation of cell growth, decrease in glycerol uptake, and reduction of 3-HP production. To reduce acetate production without modifying this gene, various aeration rates were tested in a 1-L bioreactor by applying agitation speed between 200 and 600 rotations per minute (rpm), at an air flow rate of 1 vessel volume minute (vvm). Increase in oxygen transfer enhanced cell growth 2.8-fold. 3-HP production yield was improved from 0.18 to $0.38 \mathrm{~mol}_{3}$-HP molglycerol $^{-1}$ at 200 and $600 \mathrm{rpm}$, respectively. In the same time, a drastic decrease in 1,3-PDO yield, from 
minimized at $600 \mathrm{rpm}$ but never totally suppressed (Ko et al., 2017). It is also important to keep in mind that high energy needs linked to high aeration and agitation rates contribute to expand production costs at the industrial scale. Simultaneous 3-HP and 1,3-PDO production allows performing process under low-aeration conditions as the pathway is redox balanced.

The influence of the fermentation medium composition was also assessed in several studies. Notably, part of the record-holder study of Li et al. was dedicated to this issue (Y. Li et al., 2016). 3-HP production from glycerol by K. pneumoniae was tested on different media in shake-flasks. Individual variation of each component of the medium was tested at six different levels: $0 \%, 25 \%, 50 \%, 100 \%, 150 \%, 200 \%$ (in comparison to their previous study). The optimised medium that was selected led to 1.8-fold increase in 3-HP production. Ten different levels of IPTG concentrations were also tested. Surprisingly, IPTG concentration showed no impact on growth and 3-HP production. $\mathrm{pH}$ was also showed to be a critical factor to 3-HP production by K. pneumoniae. The adequate $\mathrm{pH}$ value that was chosen was 7.0 , because it corresponded to the highest glycerol conversion to 3-HP (Y. Li et al., 2016). A study on medium optimisation of growth medium for Lactobacillus reuteri was also carried out by Couvreur et al. They screened 30 different media, varying by their concentrations of carbon source (sugar beet and wheat processing coproducts), yeast extract, tween 80 and vitamin $\mathrm{B}_{12}$. In the case of L. reuteri, bacterial growth is separated from glycerol conversion in two distinct steps (see part 3.2, Fig. 4). Couvreur et al. studied the impact of the medium composition of the growth step on the performances of the second step. They showed that the optimal medium could lead to an increase of $70 \%$ in subsequent 3-HP production, with reduced 3HPA titre (Couvreur et al., 2017).

\subsection{Multi-step and integrated approaches}

Recently, process approaches to 3-HP bioproduction have been diversifying. In order to improve the yield and selectivity of the overall process, multiple-step integrated processes are being designed. This is especially true for 3-HP production from glycerol. The first step consists of the conversion of glycerol into either 3-HPA or a mix of 3-HP and 1,3-PDO. The undesired product (3-HPA or 1,3-PDO) is subsequently converted into 3-HP (Figure 4). Sabet-Azad et al. implemented a two-step process involving both wild-type and recombinant organisms (Sabet-Azad et al., 2015). Glycerol was first supplied in fed-batch mode to wildtype Lactobacillus reuteri, which converted it into 3-HPA mostly (56 \% of the amount of 
products), along with 3-HP (22\%) and 1,3-PDO (22\%). By coupling this step with an in situ 3-HPA complexation with bisulfite and an extractive module, a 3-HPA solution free of 3-HP and 1,3-PDO, could be obtained. 3-HPA was then converted in fed-batch mode either by growing cells or by resting cells of a recombinant $E$. coli. When using resting cells, this second step reached a $1.1 \mathrm{~g} \mathrm{~L}^{-1} 3$-HP titre, with a $0.06 \mathrm{~g} \mathrm{~L}^{-1} \mathrm{~h}^{-1}$ productivity. Interestingly, no by-product was obtained along with 3-HP. This approach provides another way to circumvent the contradiction between the optimisation of cobalamin availability and $\mathrm{NAD}^{+}$regeneration (see part 2.3). By using the 3-HPA accumulating bacterium L. reuteri, it is possible to separate the anaerobic, cobalamin-dependent step (from glycerol to 3-HPA) from the aerobic $\mathrm{NAD}^{+}$-dependent step (from 3-HPA to 3-HP-CoA). Then, each step can be optimised separately, according to its specificities. Zhao et al. and Dishisha et al. implemented two step processes during which glycerol was first converted respectively into 1,3-PDO by growing Klebsiella pneumoniae in batch mode or into a mix of 1,3-PDO and 3-HP by resting Lactobacillus reuteri in fed-batch mode (Dishisha et al., 2015; Zhao et al., 2015). Then, resting cells of acetic acid bacterium Gluconobacter oxydans were used to convert 1,3-PDO to 3-HP. In the first study, G. oxydans was implemented in the same bioreactor as $K$. pneumoniae, after the latter was heat inactivated at $65^{\circ} \mathrm{C}$ during $30 \mathrm{~min}$. The overall process reached a $60.5 \mathrm{~g} \mathrm{~L}^{-1} 3$-HP titre, corresponding to a 0.52 molc molc $^{-1}$ yield on glycerol and a 0.94 molC molC $^{-1}$ yield on 1,3-PDO (Zhao et al., 2015). The second process implemented G. oxydans in a separate batch from L. reuteri. Glycerol bioconversion by L. reuteri produced an equimolar mix of 1,3-PDO and 3-HP. The supernatant was given as bioconversion medium to G. oxydans, which quantitatively and selectively oxidized 1,3-PDO to 3-HP in less than 5 hours. The process reached a final 3-HP titre of $23.6 \mathrm{~g} \mathrm{~L}^{-1}$ (Dishisha et al., 2015). This additional bioconversion step allows an increase in the maximal theoretical 3-HP yield to 1 mol3-HP mol$^{-1}$ glycerol, which is not achievable when using K. pneumoniae or L. reuteri alone (see part 2.2). Despite the attractiveness multi-step processes may have, particularly regarding overall yields, their economic feasibility is questionable. Indeed, their practical implementation is likely to prove too constraining, with higher associated costs, in comparison to a single-step fermentation. Still, these studies open up new perspectives, notably towards integrated continuous processes. Continuous processes have great industrial interest due to reduced operating costs. Moreover, dual-microbe strategies may be seen as a first step towards implementation of both pathways into a single microbial chassis, or towards mixed cultures for 3-HP production. 
An important characteristic of these studies is that at least one step is performed by resting cells (Figure 4). Resting cells are also used for 3-HP production from 3-HPN, which is carried out by Comamonas testosteroni or recombinant E. coli (Hann et al., 2003; Yu et al., 2016). Generally speaking, when resting cells are used for bioconversions, a preliminary step is required in order to produce the necessary biomass of whole cell biocatalyst. It is thus beneficial to recycle resting cells through several batches: the more bioconversion batches can be carried out from a single biomass production, the more cost-effective the process gets. Cell recycling in the context of 3-HP production was reported in several studies and was achieved by cell immobilisation on alginate beads (Hann et al., 2003; J. Li et al., 2016; Yu et al., 2016), by cryostructured cross-linking (Zaushitsyna et al., 2017), or by microfiltration (Dishisha, 2013). Hann et al. and Yu et al. used C. testosteroni and E. coli respectively for 3-HPN conversion to 3-HP, while Li et al. implemented the acetic acid bacteria Acetobacter sp. CGMCC 8142 for 3-HP production from 1,3-PDO. C. testosteroni and E. coli cells were recycled many times: up to 100 cycles for the former, and up to 74 cycles for the latter. As for it, the study on Acetobacter sp. CGMCC 8142 focused on a more restricted number of cycles: 5 consecutive batches were performed. In each study, significant enzymatic activities were retained after the successive cycles, for instance E. coli retained $70 \%$ of its enzymatic activity after 74 batches. When compared to suspended cells, it was shown that immobilised cells could retain their ability to produce 3-HP over a greater number of cycles. Suspended cells of E. coli could not produce 3-HP after the tenth batch, while immobilised cells could still convert 3-HPN to 3-HP after the $60^{\text {th }}$ batch with a molar yield ranging from 0.4 to $0.9 \mathrm{~mol}_{3-\mathrm{HP}}$ mol$_{3-\mathrm{HPN}^{-1}}$, depending on the immobilisation material (Yu et al., 2016). After 5 cycles,

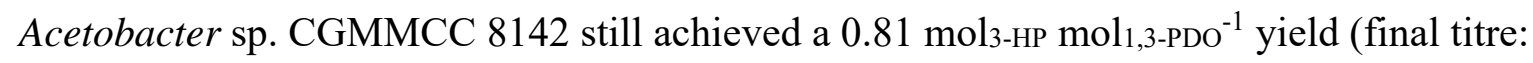
$47.8 \mathrm{~g} \mathrm{~L}^{-1}$; productivity: $0.8 \mathrm{~g} \mathrm{~L}^{-1} \mathrm{~h}^{-1}$ ), while the yield of suspended cells was already below

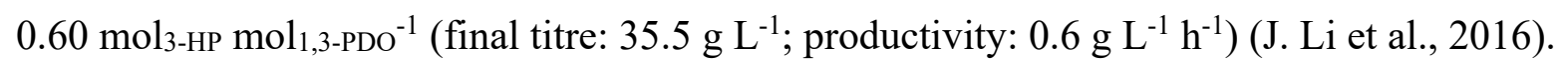
In the Hann et al. study, molar yields are not given, but productivities are remarkably high: 23 $\mathrm{g} \mathrm{L}^{-1} \mathrm{~h}^{-1}$ for the first batch and $7 \mathrm{~g} \mathrm{~L}^{-1} \mathrm{~h}^{-1}$ for the last one (Hann et al., 2003). These 3-HP productivities are the highest ones reported so far for a single-step microbial process (Table 1). This can be attributed, at least partly, to the high biocatalyst density that was used: given the data available in the paper, the cell load can be estimated around $19 \mathrm{~g}_{\mathrm{cdw}} \mathrm{L}^{-1}$. In comparison, J. Li et al. used a $5 \mathrm{~g}_{\mathrm{cdw}} \mathrm{L}^{-1}$ cell load. Yu et al. reached a $36.9 \mathrm{~g} \mathrm{~L}^{-1} \mathrm{~h}^{-1}$ productivity, but this value accounts for 3-HP obtained after isolation and purification of the production of the first 30 cycles. Interestingly, it was also shown that cell immobilisation improved their tolerance to the substrate (1,3-PDO or 3-HPN). Like this, higher 3-HP titres 
can be reached with immobilised cells, in comparison to suspended cells. For instance, immobilized Acetobacter sp. CGMCC 8142 were able to produce $67.0 \mathrm{~g} \mathrm{~L}^{-1} 3$-HP from $70 \mathrm{~g}$ $\mathrm{L}^{-1} 1,3$-PDO compared to $50.4 \mathrm{~g} \mathrm{~L}^{-1} 3$-HP in the case of suspended cells, which corresponds to a 1.32-fold higher molar yield (J. Li et al., 2016). In the same manner, immobilized E. coli cells reached a complete hydrolysis of $497 \mathrm{~g} \mathrm{~L}^{-1} \mathrm{HPN}$ within $24 \mathrm{~h}$ while free cells were not able to cope with more than $320 \mathrm{~g} \mathrm{~L}^{-1}$. Thus, cell immobilisation appears as a suitable solution to one of the issues pointed out by Kumar et al. in 2013. Indeed, they identified that metabolite toxicity (3-HPA and 3-HP in particular, but it also applies to substrates) is one of the key issues to address before commercial 3-HP bioproduction can be considered. Another advantage of using cell immobilisation techniques is that they facilitate subsequent downstream processes. Indeed, the filtration step usually needed for cell removal, can be skipped. In case of in situ product recovery, cell immobilisation could help reduce the toxic effect of the extractant phase (see part 4). In order to allow a scale up of immobilisation techniques, special attention should be paid to the bioreactor design, so that process performances are not hindered by mass transfer limitations. The issue of mass transfer was recently addressed by Zaushitsyna et al. who evaluated a novel immobilisation technique by direct aggregation of recombinant $L$. reuteri cells for the conversion of glycerol into 3-HPA, 3-HP and 1,3-PDO (Zaushitsyna et al., 2017). Dry cell pellets were mixed with glutaraldehyde, oxidized dextran or a mix of activated polyethyleneimine(PEI)/modified polyvinyl alcohol (PVA) used as various crosslinkers. After freezing at $-12^{\circ} \mathrm{C}$ for 3 days, these cryogels were characterized in terms of structural and mechanical stability, elastic strength, and porosity. Cell load and retaining, preservation of cell viability, and maintenance of metabolic and catalytic activities were also assessed to compare impacts of crosslinkers. On the basis of these results, the PEI/PVA $(0.55 / 0.35 \% \mathrm{w} / \mathrm{v}) \mathrm{mix}$ was retained for glycerol conversion. After packing into cylindrical glass column, embedded resting cells were used for 3-HP production performed in fed-batch mode. At a very low glycerol feeding rate of $3 \mathrm{mg} \mathrm{h}^{-}$ 1, $3.3 \mathrm{~g} \mathrm{~L}^{-1}$ 3-HP were produced (productivity: $0.09 \mathrm{~g} \mathrm{~L}^{-1} \mathrm{~h}^{-1}$; molar yield: 0.48 mol3-HP molglycerol $^{-1}$ ) with 1,3-PDO as obligate co-product (Zaushitsyna et al., 2017). These results are three times lower than that reported earlier for free cells (Dishisha et al., 2014). This was explained by adverse conditions encountered by cells during cryostructuration process and conversion step by itself. In spite of these low performances, this study offers interesting perspectives in order to overcome mass transfer limitations in cell immobilisation processes. Several improvements were suggested by the authors: limiting oxygen exposure during cryogel preparation, increasing biocatalyst load, and optimising column packing (Zaushitsyna 
et al., 2017).

\section{Downstream processes}

Final product recovery is a critical step for the commercialisation of bio-based compounds, especially in the case of 3-HP. Several aspects make 3-HP recovery in high concentrations and purity, especially challenging: (i) when produced by bioconversion with cells, 3-HP is dissolved in a complex culture medium, at a relatively low concentration; (ii) being a carboxylic acid of low molecular weight, it is very soluble in aqueous media; and (iii) traditional distillation techniques are not effective because 3-HP decomposes at high temperatures and easily polymerises at high concentrations (Hoppe et al., 2016). Because of that, downstream steps can represent an important percentage of total production cost. For carboxylic acids, this percentage can go from $20 \%$ to $60 \%$ (Hoppe et al., 2016; Straathof, 2011), so it is not surprising that 3-HP is commercially available as a $30 \%$ aqueous solution and at a relatively high price.

910

Attempts have been made in order to overcome these difficulties and decrease recovery and purification costs. Quite complete reviews of carboxylic acid recovery are given by LópezGarzón and Straathof (2014) and Murali et al. (2017), where the main primary recovery processes described are: adsorption, liquid-liquid extraction, salt precipitation, filtration, and electrodialysis (López-Garzón and Straathof, 2014; Murali et al., 2017). Although the selection of the best process varies in the literature because of the difference in properties of carboxylic acids, in situ product recovery (ISPR) by extraction during bioconversion has been the most popular approach. This strategy has been proven to improve productivity and yield of several carboxylic acid production processes.

Until just recently, there were no studies in the literature focused on ISPR techniques for 3HP. However, it could be assumed that processes which proved to be effective for the extraction of carboxylic acids of similar molecular structures may also work for 3-HP. For example, 2-hydroxypropionic acid, also known as lactic acid, is a positional isomer of 3-HP. The recovery of this molecule from fermentation broths has been widely studied, and the ISPR approach has proved to enhance the productivity and yield of several lactic acid production processes (Boonmee et al., 2016; Gao et al., 2009; Wasewar et al., 2004). Liquidliquid reactive extraction stands out from the other approaches studied, because it can 
selectively remove acids from diluted solutions. Like this, 3-HP is continuously removed during its production and is not accumulated in the fermentation broth. This should help relieve the microorganisms from the acidic stress. This method is performed in two stages: the first consists in solute extraction through an organic acid-base complex formation; and the second stage is the regeneration of the extractant phase by stripping the solute from the organic complex using another aqueous phase. This second step is also known as back extraction (Datta et al., 2015)

Based on this, Moussa et al. made a comparative study of 3-HP and lactic acid behaviour during reactive extraction (Moussa et al., 2015). They used different concentrations of tri-noctylamine (TOA) and tri-n-octylmethylammonium chloride (Aliquat 336) as extractants, since they have exhibited good extraction performances on lactic acid (Wasewar et al., 2004; Yankov et al., 2004). Both compounds were diluted in n-decanol. Solutions of $1 \mathrm{~g} \mathrm{~L}^{-1}$ of each acid where extracted with organic phases. $\mathrm{pH}$ of these solutions was 2.9 and 3.2 for lactic acid and 3-HP, respectively. Lactic acid was better extracted than 3-HP for all extractant concentrations. This was related to the stronger acidity of lactic acid $(\mathrm{pKa}=3.86)$ compared to that of 3-HP $(\mathrm{pKa}=4.51)$, since the interaction between the acid and the extractant is stronger (Tamada and King, 1990). However, results obtained for 3-HP were encouraging with high distribution coefficients over a wide range of experimental conditions, including 3HP dissolved in real fermentation broth. In the latter case, the highest performances were achieved using a mix of TOA $(10 \% \mathrm{vol} / \mathrm{vol})$ and Aliquat $336(10 \% \mathrm{vol} / \mathrm{vol})$ : the extraction yield reached $62 \%$ and the selectivity for $3-\mathrm{HP}$ was $\alpha_{3-\mathrm{HP}}=15.7 \%$ (Moussa et al., 2015). Selectivity $\left(\alpha_{3}-\mathrm{HP}\right)$ was defined as the ratio of extracted 3-HP to the total amount of extracted molecules (3-HP + 3-HPA + glycerol + 1,3-PDO).

Afterwards, Burgé et al. evaluated the reactive extraction of 3-HP on a hollow fibres membrane contactor, using the organic phases compositions mentioned above (Burgé et al., 2016). This experimental configuration displays advantages that make it a good candidate for extractive fermentation: (i) dispersion between phases is avoided, as well as a subsequent separation step between organic and aqueous phases; (ii) direct contact with microorganisms is significantly reduced, thus enhancing the biocompatibility of the process; and (iii) hollow fibre configuration offers a high interfacial area, which generally improves both the product transfer to the extractant phase and the process compactness (Drioli et al., 2006; Gabelman and Hwang, 1999). They obtained higher distribution coefficients $\left(\mathrm{K}_{\mathrm{D}}\right)$ and yields in 
comparison to reactive extraction of the same solutions in separatory funnels: $\mathrm{K}_{\mathrm{D}}=3.05$ versus $\mathrm{K}_{\mathrm{D}}=2.44$ and $\mathrm{Y}=75.3 \%$ versus $\mathrm{Y}=71 \%$ respectively, thus demonstrating the potential of this configuration. Further optimisation studies were reported and consist of a screening of solvents used as extractant phase, and of a detailed study of 3-HP extraction mechanism. It has been found that tertiary amines like TOA, have a better extraction performance when diluted in active solvents like long chain alcohols, since they act as proton donors, which improves the acid-amine complex solvation in the organic phase (Chemarin et al., 2017a). Also, mathematical models that take into account complexation-solvation mechanisms of 3-HP extraction have been developed (Chemarin et al., 2017b). This approach of process optimisation is a promising tool for its use on carboxylic acids extraction.

Biocompatibility is a key factor for ISPR systems: it is known that for reactive extraction, finding a biocompatible organic phase with good extraction performance is challenging. For example, although Aliquat 336 addition to the extractant phase improves the reaction performance, it has been found to be very toxic to bacteria, even at low concentrations (Kumar et al., 2012). Therefore, Aliquat 336 cannot be considered as a good candidate for extractive bioconversion. Because of the promising results mentioned above, extraction with TOA diluted in decanol, assisted by a hollow fibres membrane contactor, was evaluated for the extraction of 3-HP produced by Lactobacillus reuteri. Unfortunately, the ISPR system had a significant inhibition effect over 3-HP bioproduction, resulting in lower titres when compared to bioconversion alone (Burgé et al., 2017). This was attributed to the high toxicity of the organic phase, despite the use of the membrane contactor. This is why it is important to find a compromise between extraction performance and the biocompatible ISPR process used. Some good approaches might be (i) screening for more biocompatible solvents, and (ii) changing the membrane material of the hollow fibres contactor, in order to reduce direct contact of the bioconversion medium with the organic phase.

Currently, several patents describe purification processes applied to 3-HP (Abraham et al., 2014; Hoppe et al., 2016; Meng et al., 2006; Tengler and DeCoster, 2013). They include an initial clarification of the aqueous phase to remove cells and other solids of the bioconversion medium, so they do not comprise ISPR. 3-HP primary recovery consists of different strategies that combine classical separation processes like salt precipitation and liquid extraction with solvents, and is followed by evaporation and/or distillation. The compositions resulting from the methods used may deliver a highly pure $3-\mathrm{HP}$, from $70 \%$ up to $99.5 \%$; and in 
concentrations that vary from $30 \%$ up to $95 \%$ (weight/volume). However, reaching the maximal concentration and purity represents high energetic costs and makes the economic viability of the overall process questionable. This is why, obtaining an aqueous solution of 3HP that already has both high purity and high concentration could significantly reduce the cost of further purification steps, and in situ reactive extraction may play an important role in delivering this objective. One of the most appealing advantages over traditional processes is that, with the adequate back extraction strategy, the product can be recovered in the form of the acid and not as a salt. Studies of other similar organic acids have shown that the temperature swing, diluent swing, and using a volatile base, such as trimethylamine, in the stripping phase, enables obtaining the acid form and could be an interesting approach for the recovery of 3-HP (Keshav and Wasewar, 2010). Further research is needed in order to integrate the constraints of both microbial production and downstream steps.

\section{Conclusions and perspectives}

In recent years important progress in 3-HP bioproduction has been made, thanks to everincreasing research and industrial interest. Research efforts are mainly dedicated to the metabolic engineering of the various metabolic pathways and microbial hosts. Given the great variety of possible substrates, metabolic pathways, microbial agents, and process techniques, it can be expected that the future of 3-HP production is likely to be diverse. Recent studies have notably benefited from the development of synthetic biology tools, such as metabolite sensors, CRISPR-Cas systems for genetic editing, dynamic flux control, and omics and in silico techniques. Yet, research is now also focusing on process engineering and downstream processes. Various fermentation strategies are currently under investigation, including onestep fed-batch, electro-fermentation, multi-step and integrated processes. As for them, downstream processes are however mainly focused on in situ product recovery. These fermentation and extractive strategies form a complementary approach to metabolic engineering, towards sustainable and economically viable 3-HP production.

Industrial manufacturers' attention is essentially drawn by the possibility of converting 3-HP into acrylic acid in one step only. Indeed, acrylic acid is one of the most produced commodities and its production relies on petro-chemical processes. Bio-based acrylic acid production through 3-HP is a very promising strategy toward greener and less petroldependent processes. This is in any case the approach that was initiated by the industrial 
consortium composed of Novozymes and Cargill. Other companies, such as BASF and P\&G, have recently been patenting catalytic methods for dehydrating 3-HP to acrylic acid, thus proving their interest for bio-based acrylic acid (Blaschke et al., 2016; Velasquez et al., 2017). However, it is still unknown to what extent bio-based acrylic acid production is less energy consuming and less greenhouse gas emitting in comparison to petro-chemically-based acrylic acid. Still, a study published in 2014 assessed the life-cycle fossil energy consumption and greenhouse gas emissions of acrylic acid produced from 3-HP in comparison to fossil-based acrylic acid (Adom et al., 2014). It was estimated that bio-based acrylic acid led to a $53 \%$ reduction in greenhouse gas emissions and to $58 \%$ less fossil fuel consumption. It can be expected in the coming years that the production of bio-based chemicals through biotechnological processes will continue to develop, encouraged by public policies. For instance, the European Commission has designated bio-based chemical production and bioprocesses as priority areas for investments (European Commission, 2014). However, when assessing the commercial feasibility of a new process, one has to take into account the risk of the investment, which mostly relies on the prices of raw materials. Given the low price of petrol and the volatility of substrate prices such as glycerol or glucose, it can be expected that bio-based 3-HP will not be competitive with fossil-based acrylic acid in the next years. Furthermore, because of the price volatility of carbon substrates it is difficult to make forecasts, thus investments in biotechnological processes remain risky. These limitations might hinder the commercial development of 3-HP in the coming years. Nevertheless, the company Verdant Bioproducts Limited built the first biorefinery plant aiming at producing 3$\mathrm{HP}$ - among other commodities - from waste $\mathrm{CO}_{2}$.

\section{Despite this context, significant progress has been made in the production of 3-HP. Due to} some of these improvements, the results of certain process indicators are getting closer to industrial relevance, notably in terms of final titres, the highest so far being $83.8 \mathrm{~g} \mathrm{~L}^{-1}$. Since most studies are essentially proofs of concept for new recombinant strains, processes are not fully optimized and productivity in particular remains relatively low. In the report published in 2004 by the US DoE, it was estimated that a minimal productivity of $2.5 \mathrm{~g} \mathrm{~L}^{-1} \mathrm{~h}^{-1}$ is required for 3-HP production to be economically competitive. To this day and according to the scientific literature, this threshold has rarely been crossed. The progress made to date has been possible thanks to intensive efforts in genetic engineering. Physiology of the different producer strains now needs to be characterised in detail for processes to be further optimised. As such, modelling works that have already been carried out have been of great help for better 
understanding microbial metabolisms for 3-HP production. Process approaches, such as multi-stepping, are starting to be developed, which should enable improve performances. Immobilisation technologies may mark a step toward continuous process, and these are often preferred in industry due to their cost efficiency and their robustness. With the combination of genetic engineering and process approaches, some of the metabolic hurdles, such as toxicity of some products or redox limitations, are being overcome. Some approaches are however still in their infancy: electro-fermentation in particular offers exciting possibilities for enhancing 3-HP synthesis, but it still requires intensive research efforts before it can be scaled up.

Until now, 3-HP production was mostly attempted from glycerol or glucose as a carbon source. However, some recent studies also achieved 3-HP production from other carbon sources of interest, such as $\mathrm{CO}_{2}$ and xylose, although performances are still low. It should however be noted that almost no attempt has been made at producing 3-HP from crude industrial by-products, even though it could be very interesting to develop in the context of biorefinery. Only a recent study focused on L. reuteri's growth on wheat and sugar beet byproducts (Couvreur et al., 2017). 3-HP production has not yet been attempted using crude glycerol: it is however an important issue to address before commercial production can be considered. Indeed, crude glycerol may contain some impurities that are toxic to cells. Finally, downstream processes for 3-HP extraction and purification will benefit from the experience gained with other organic acids, such as lactic acid in particular. However, the specificities of 3-HP extraction are still to be addressed. Downstream processes hold a central place of the overall process because they are indispensable and they account for an important part of the total cost. In this respect, an integrated approach of in situ extraction coupled to the fermentation or bioconversion step is promising.

\section{Acknowledgments}

The authors would like to thank Chandanie Hunter Spinnler and Amélie Girardeau for kindly correcting the English of the manuscript. The $\mathrm{Ph}$. D grants of Florence de Fouchécour and Ana-Karen Sánchez Castañeda were kindly awarded respectively by the doctoral school ABIES of the University Paris Saclay, and the CONACyT of Mexico.

\section{Declaration of interest}


1099

1100 The authors declare that they have no competing interests. 


\section{References}

Abraham, T.W., Allen, E., Bohnert, E.C., Frank, C.L., Hahn, J.J., Tsobanakis, P., 2014. Recovery of 3-hydroxypropionic acid. WO2014144367.

Adachi, O., Miyagawa, E., Shinagawa, E., Matsushita, K., Ameyama, M., 1978a. Purification and properties of particulate alcohol dehydrogenase from Acetobacter aceti. Agric. Biol. Chem. 42, 2331-2340. doi:10.1080/00021369.1978.10863357

Adachi, O., Tayama, K., Shinagawa, E., Matsushita, K., Ameyama, M., 1980. Purification and characterization of membrane-bound aldehyde dehydrogenase from Gluconobacter suboxydans. Agric. Biol. Chem. 44, 503-515. doi:10.1080/00021369.1980.10863997

Adachi, O., Tayama, K., Shinagawa, E., Matsushita, K., Ameyama, M., 1978b. Purification and characterization of particulate alcohol dehydrogenase from Gluconobacter suboxydans. Agric. Biol. Chem. 42, 2045-2056. doi:10.1080/00021369.1978.10863306

Adams, B.L., 2016. The Next Generation of Synthetic Biology Chassis: Moving Synthetic Biology from the Laboratory to the Field. ACS Synth. Biol. 5, 1328-1330. doi:10.1021/acssynbio.6b00256

Adom, F., Dunn, J.B., Han, J., Sather, N., 2014. Life-Cycle Fossil Energy Consumption and Greenhouse Gas Emissions of Bioderived Chemicals and Their Conventional Counterparts. Environ. Sci. Technol. 48, 14624-14631. doi:10.1021/es503766e

Ameyama, M., Osada, K., Shinagawa, E., Matsushita, K., Adachi, O., 1981. Purification and characterization of aldehyde dehydrogenase of Acetobacter aceti. Agric. Biol. Chem. 45, 1889-1890. doi:10.1080/00021369.1981.10864803

Amin, H.M., Hashem, A.M., Ashour, M.S., Hatti-Kaul, R., 2013. 1,2 Propanediol utilization by Lactobacillus reuteri DSM 20016, role in bioconversion of glycerol to 1,3 propanediol, 3-hydroxypropionaldehyde and 3-hydroxypropionic acid. J. Genet. Eng. Biotechnol. 11, 53-59. doi:10.1016/j.jgeb.2012.12.002

Andersen, G., Björnberg, O., Polakova, S., Pynyaha, Y., Rasmussen, A., Møller, K., Hofer, A., Moritz, T., Sandrini, M.P.B., Merico, A.-M.M., Compagno, C., Åkerlund, H.E., Gojković, Z., Piškur, J., 2008. A second pathway to degrade pyrimidine nucleic acid precursors in eukaryotes. J. Mol. Biol. 380, 656-666. doi:10.1016/j.jmb.2008.05.029

Andreeßen, B., Taylor, N., Steinbüchel, A., Andreessen, B., Taylor, N., Steinbuechela, A., 2014. Poly(3-hydroxypropionate): A promising alternative to fossil fuel-based materials. Appl. Environ. Microbiol. 80, 6574-6582. doi:10.1128/AEM.02361-14

Ansede, J.H., Pellechia, P.J., Yoch, D.C., 1999. Metabolism of acrylate to beta- 
hydroxypropionate and its role in dimethylsulfoniopropionate lyase induction by a salt marsh sediment bacterium, Alcaligenes faecalis M3A. Appl. Environ. Microbiol. 65, $5075-5081$.

Barnhart, M., Negrete-Raymond, A., Frias, J., Barbier, G., Catlett, M., 2015. 3Hydroxypropionic Acid Production by Recombinant Yeasts Expressing an Insect Aspartate 1-Decarboxylase. WO2015017721.

Basan, M., Hui, S., Okano, H., Zhang, Z., Shen, Y., Williamson, J.R., Hwa, T., 2015. Overflow metabolism in Escherichia coli results from efficient proteome allocation. Nature 528, 99-104. doi:10.1038/nature15765

Becker, J., Wittmann, C., 2012. Bio-based production of chemicals, materials and fuels Corynebacterium glutamicum as versatile cell factory. Curr. Opin. Biotechnol. 23, 631640. doi:10.1016/J.COPBIO.2011.11.012

Berg, I.A., Kockelkorn, D., Buckel, W., Fuchs, G., 2007. A 3-Hydroxypropionate/4Hydroxybutyrate Autotrophic Carbon Dioxide Assimilation Pathway in Archaea. Science (80-. ). 318, 1782-1786. doi:10.1126/science.1149976

Biebl, H., Menzel, K., Zeng, A.-P.P., Deckwer, W.-D.D., 1999. Microbial production of 1,3propanediol. Appl. Microbiol. Biotechnol. 52, 289-297. doi:10.1007/s002530051523

Bindel, M., 2014. 3-Hydroxypropionic Acid Production by Recombinant Yeasts. WO2014085330.

Blaschke, T., Lang, O., Koch, S., Hartmann, M., 2016. Method for the Dehydration of 3Hydroxypropanoic Acid to Form Acrylic Acid. WO2016162175 A1.

Boonmee, M., Cotano, O., Amnuaypanich, S., Grisadanurak, N., 2016. Improved Lactic Acid Production by In Situ Removal of Lactic Acid During Fermentation and a Proposed Scheme for Its Recovery. Arab. J. Sci. Eng. 41, 2067-2075. doi:10.1007/s13369-015$1824-5$

Borodina, I., Kildegaard, K.R., Jensen, N.B., Blicher, T.H., Maury, J., Sherstyk, S., Schneider, K., Lamosa, P., Herrgård, M.J., Rosenstand, I., Öberg, F., Forster, J., Nielsen, J., 2015. Establishing a synthetic pathway for high-level production of 3hydroxypropionic acid in Saccharomyces cerevisiae via beta-alanine. Metab. Eng. 27, 57-64. doi:10.1016/j.ymben.2014.10.003

Bozell, J.J., Petersen, G.R., 2010. Technology development for the production of biobased products from biorefinery carbohydrates - the US Department of Energy's "Top 10" revisited. Green Chem. 12, 539-554. doi:10.1039/b922014c

Bramucci, M.G., Dicosimo, R., Fallon, R.D., Gavagan, J.E., Herkes, F., Wilczek, L., 2002. 3- 
hydroxycarboxylic acid production and use in branched polymers. WO 2002012530.

Branco dos Santos, F., Du, W., Hellingwerf, K.J., 2014. Synechocystis: Not Just a Plug-Bug for CO2, but a Green E. coli. Front. Bioeng. Biotechnol. 2, 36. doi:10.3389/fbioe.2014.00036

Buchholz, K., Collins, J., 2013. The roots-a short history of industrial microbiology and biotechnology. Appl. Environ. Microbiol. 97, 3747-3762. doi:10.1007/s00253-0134768-2

Burgé, G., Chemarin, F., Moussa, M., Saulou-Bérion, C., Allais, F., Spinnler, H.-E., Athes, V., 2016. Reactive extraction of bio-based 3-hydroxypropionic acid assisted by hollowfiber membrane contactor using TOA and Aliquat 336 in n-decanol. J. Chem. Technol. Biotechnol. 91, 2705-2712. doi:10.1002/jctb.4878

Burgé, G., Moussa, M., Saulou-Bérion, C., Chemarin, F., Kniest, M., Allais, F., Spinnler, H.E., Athès, V., 2017. Towards an extractive bioconversion of 3-hydroxypropionic acid: study of inhibition phenomena. J. Chem. Technol. Biotechnol. 92, 2425-2432. doi:10.1002/jctb.5253

Burgé, G., Saulou-Bérion, C., Moussa, M., Pollet, B., Flourat, A., Allais, F., Athès, V., Spinnler, H.E., 2015. Diversity of Lactobacillus reuteri Strains in Converting Glycerol into 3-Hydroxypropionic Acid. Appl. Biochem. Biotechnol. 177, 923-939. doi:10.1007/s12010-015-1787-8

Cao, A., Kasuya, K., Abe, H., Doi, Y., Inoue, Y., 1998. Studies on comonomer compositional distribution of the bacterial poly(3-hydroxybutyric acid-co-3-hydroxypropionic acid)s and crystal and thermal characteristics of their fractionated component copolyesters. Polymer (Guildf). 39, 4801-4816. doi:10.1016/S0032-3861(97)10146-X

Casas, I.A., Dobrogosz, W.J., 2000. Validation of the Probiotic Concept: Lactobacillus reuteri Confers Broad-spectrum Protection against Disease in Humans and Animals. Microb. Ecol. Health Dis. 12, 247-285. doi:10.1080/08910600050216246-1

Chemarin, F., Moussa, M., Allais, F., Athès, V., Trelea, I.C., 2017a. Mechanistic modeling and equilibrium prediction of the reactive extraction of organic acids with amines: A comparative study of two complexation-solvation models using 3-hydroxypropionic acid. Sep. Purif. Technol. 189, 475-487. doi:10.1016/j.seppur.2017.07.083

Chemarin, F., Moussa, M., Chadni, M., Pollet, B., Lieben, P., Allais, F., Trelea, I.C., Athès, V., 2017b. New insights in reactive extraction mechanisms of organic acids: An experimental approach for 3-hydroxypropionic acid extraction with tri- $\mathrm{n}$-octylamine. Sep. Purif. Technol. 179, 523-532. doi:10.1016/j.seppur.2017.02.018 
Chen, X., Yang, X., Shen, Y., Hou, J., Bao, X., 2017. Increasing Malonyl-CoA Derived Product through Controlling the Transcription Regulators of Phospholipid Synthesis in Saccharomyces cerevisiae. ACS Synth. Biol. 6, 905-912. doi:10.1021/acssynbio.6b00346

Chen, Y., Bao, J., Kim, I.-K., Siewers, V., Nielsen, J., 2014. Coupled incremental precursor and co-factor supply improves 3-hydroxypropionic acid production in Saccharomyces cerevisiae. Metab. Eng. 22, 104-109. doi:10.1016/j.ymben.2014.01.005

Chen, Z., Huang, J., Wu, Y., Wu, W., Zhang, Y., Liu, D., 2017. Metabolic engineering of Corynebacterium glutamicum for the production of 3-hydroxypropionic acid from glucose and xylose. Metab. Eng. 39, 151-158. doi:10.1016/j.ymben.2016.11.009

Chen, Z., Liu, D., 2016. Toward glycerol biorefinery: metabolic engineering for the production of biofuels and chemicals from glycerol. Biotechnol. Biofuels 9. doi:10.1186/s13068-016-0625-8

Cheng, K.-K., Liu, H.-J., Liu, D.-H., 2005. Multiple growth inhibition of Klebsiella pneumoniae in 1,3-propanediol fermentation. Biotechnol. Lett. 27, 19-22. doi:10.1007/s10529-004-6308-8

Choi, S., Song, C.W., Shin, J.H., Lee, S.Y., 2015. Biorefineries for the production of top building block chemicals and their derivatives. Metab. Eng. 28, 223-239. doi:10.1016/j.ymben.2014.12.007

Chu, H.S., Kim, Y.S., Lee, C.M., Lee, J.H., Jung, W.S., Ahn, J.-H., Song, S.H., Choi, I.S., Cho, K.M., 2015. Metabolic engineering of 3-hydroxypropionic acid biosynthesis in Escherichia coli. Biotechnol. Bioeng. 112, 356-364. doi:10.1002/bit.25444

Clomburg, J.M., Gonzalez, R., 2013. Anaerobic fermentation of glycerol: a platform for renewable fuels and chemicals. Trends Biotechnol. 31, 20-28. doi:10.1016/j.tibtech.2012.10.006

Couvreur, J., Teixeira, A., Allais, F., Spinnler, H.-E., Saulou-Bérion, C., Clément, T., 2017. Wheat and Sugar Beet Coproducts for the Bioproduction of 3-Hydroxypropionic Acid by Lactobacillus reuteri DSM17938. Fermentation 3, 32. doi:10.3390/fermentation3030032

Datta, D., Kumar, S., Uslu, H., 2015. Status of the Reactive Extraction as a Method of Separation. J. Chem. 2015, 1-16. doi:10.1155/2015/853789

Dave, H., Ramakrishna, C., Desai, J.D., 1996. Degradation of acrylic acid by fungi from petrochemical activated sludge. Biotechnol. Lett. 18, 963-964. doi:10.1007/BF00154630

David, F., Nielsen, J., Siewers, V., 2016. Flux Control at the Malonyl-CoA Node through Hierarchical Dynamic Pathway Regulation in Saccharomyces cerevisiae. ACS Synth. 
David, Y., Hoon Oh, Y., Babylon, M.G., Baritugo, K.-A., Joo, J.C., Chae, C.G., Kim, Y.J., Park, S.J., 2017. 14. Microbial Production of 3-Hydroxypropionic acid, in: Wittmann, L.C., Liao, J.C. (Eds.), Industrial Biotechnology: Products and Processes. Weinheim, Germany, pp. 411-451. doi:10.1002/9783527807833.ch14

Deppenmeier, U., Ehrenreich, A., 2009. Physiology of acetic acid bacteria in light of the genome sequence of Gluconobacter oxydans. J. Mol. Microbiol. Biotechnol. 16, 69-80. doi:10.1159/000142895

Dishisha, T., 2013. Microbial Production of Bio-Based Chemicals: A Biorefinery Perspective. Lund University.

Dishisha, T., Pereyra, L.P., Pyo, S.-H.H., Britton, R.A., Hatti-Kaul, R., 2014. Flux analysis of the Lactobacillus reuteri propanediol-utilization pathway for production of 3Microb Cell Fact 13, 76. doi:10.1186/1475-2859-13-76

Dishisha, T., Pyo, S.-H., Hatti-Kaul, R., 2015. Bio-based 3-hydroxypropionic- and acrylic acid production from biodiesel glycerol via integrated microbial and chemical catalysis. Microb. Cell Fact. 14. doi:10.1186/s12934-015-0388-0

Drioli, E., Criscuoli, A., Curcio, E., 2006. Membrane contactors : fundamentals, applications and potentialities. Elsevier.

Engels, C., Schwab, C., Zhang, J., Stevens, M.J.A., Bieri, C., Ebert, M.-O., McNeill, K., Sturla, S.J., Lacroix, C., 2016. Acrolein contributes strongly to antimicrobial and heterocyclic amine transformation activities of reuterin. Sci. Rep. 6, 36246. doi:10.1038/srep36246

European Commission, 2014. Communication from the Commission of the European Parliament, the Council, the European Economic and Social Committee and the Committe of the Regions for a European Industrial Renaissance.

Finnegan, I., 2017. Method for producing 3-hydroxypropanamide employing Acetobacter lovaniensis. WO2017130007A1.

Fuchs, G., 2011. Alternative Pathways of Carbon Dioxide Fixation: Insights into the Early Evolution of Life? Annu. Rev. Microbiol. 65, 631-658. doi:10.1146/annurev-micro090110-102801

Gabelman, A., Hwang, S.-T., 1999. Hollow fiber membrane contactors. J. Memb. Sci. 159, 61-106. doi:10.1016/S0376-7388(99)00040-X

Gao, M.-T., Shimamura, T., Ishida, N., Nagamori, E., Takahashi, H., Umemoto, S., Omasa, 
T., Ohtake, H., 2009. Extractive lactic acid fermentation with tri-n-decylamine as the extractant. Enzyme Microb. Technol. 44, 350-354. doi:10.1016/j.enzmictec.2008.12.001

Gokarn, R.R., Selifonova, O. V., Jessen, H., Gort, S.J., Selmer, T., Buckel, W., 2002. 3hydroxypropionic acid and other organic compounds. WO 02/42418 A2.

Hann, E.C., Sigmund, A.E., Fager, S.K., Cooling, F.B., Gavagan, J.E., Ben-Bassat, A., Chauhan, S., Payne, M.S., Hennessey, S.M., DiCosimo, R., 2003. Biocatalytic Hydrolysis of 3-Hydroxyalkanenitriles to 3-Hydroxyalkanoic Acids. Adv. Synth. Catal. 345, 775-782. doi:10.1002/adsc.200303007

Holo, H., 1989. Chloroflexus aurantiacus secretes 3-hydroxypropionate, a possible intermediate in the assimilation of $\mathrm{CO} 2$ and acetate. Arch. Microbiol. 151, 252-256. doi:10.1007/BF00413138

Hoppe, C., Hoyt, S.M., Tengler, R., DeCoster, D., Harkrader, B., Au-Yeung, P.H., Biswas, S., Vargas, P., Roach, R.P., Frank, T.C., 2016. 3-hydroxypropionic acid compositions. US9512057 B2.

Huang, Y., Li, Z., Shimizu, K., Ye, Q., 2013. Co-production of 3-hydroxypropionic acid and 1,3-propanediol by Klebsiella pneumoniae expressing aldH under microaerobic conditions. Bioresour. Technol. 128, 505-512. doi:10.1016/j.biortech.2012.10.143

Huang, Y., Li, Z., Ye, Q., 2016. Transcriptional Regulation of Genes Involved in 3Hydroxypropionic Acid Production in Response to Aeration of Recombinant Klebsiella pneumoniae. Appl. Biochem. Biotechnol. 178, 1129-1140. doi:10.1007/s12010-0151933-3

IPCC, 2007. Climate Change 2007: The Physical Science Basis, Contribution of working group 1 to the fourth assessment report of the intergovernmental panel on climate change. Cambridge University Press, Cambridge, United Kingdom and New York, NY, USA. doi:10.1017/CBO9781107415324.004

Jankowski, M.D., Henry, C.S., Broadbelt, L.J., Hatzimanikatis, V., 2008. Group contribution method for thermodynamic analysis of complex metabolic networks. Biophys. J. 95, 1487-1499. doi:10.1529/biophysj.107.124784

Jessen, H., Brian, R., Huryta, J., Mastel, B., Berry, A., Yaver, D., Catlett, M., Barnhart, M., 2012. Compositions and methods for 3-hydroxypropionic acid production. WO2012074818 A2.

Jessop-Fabre, M.M., Jakociunas, T., Stovicek, V., Dai, Z., Jensen, M.K., Keasling, J.D., Borodina, I., 2016. EasyClone-MarkerFree: A vector toolkit for marker-less integration of genes into Saccharomyces cerevisiae via CRISPR-Cas9. Biotechnol. J. 11, 1110- 
1117. doi:10.1002/biot.201600147

Jiang, X., Meng, X., Xian, M., 2009. Biosynthetic pathways for 3-hydroxypropionic acid production. Appl. Microbiol. Biotechnol. 82, 995-1003. doi:10.1007/s00253-009-1898-7 Jung, I.-Y., Lee, J.-W., Min, W.-K., Park, Y.-C., Seo, J.-H., 2015. Simultaneous conversion of glucose and xylose to 3-hydroxypropionic acid in engineered Escherichia coli by modulation of sugar transport and glycerol synthesis. Bioresour. Technol. 198, 709-716. doi:10.1016/j.biortech.2015.09.079

Jung, W.S., Kang, J.H., Chu, H.S., Choi, I.S., Cho, K.M., 2014. Elevated production of 3hydroxypropionic acid by metabolic engineering of the glycerol metabolism in Escherichia coli. Metab. Eng. 23, 116-122. doi:10.1016/j.ymben.2014.03.001

Kalantari, A., Chen, T., Ji, B., Stancik, I.A., Ravikumar, V., Franjevic, D., Saulou-Bérion, C., Goelzer, A., Mijakovic, I., 2017. Conversion of Glycerol to 3-Hydroxypropanoic Acid by Genetically Engineered Bacillus subtilis. Front. Microbiol. 8, 638. doi:10.3389/fmicb.2017.00638

Kandler, O., Stetter, K.-O., Köhl, R., 1980. Lactobacillus reuteri sp. nov., a New Species of Heterofermentative Lactobacilli. Zentralblatt für Bakteriol. I. Abt. Orig. C Allg. Angew. und ökologische Mikrobiol. 1, 264-269. doi:10.1016/S0172-5564(80)80007-8

Keller, M.W., Schut, G.J., Lipscomb, G.L., Menon, A.L., Iwuchukwu, I.J., Leuko, T.T., Thorgersen, M.P., Nixon, W.J., Hawkins, A.S., Kelly, R.M., Adams, M.W.W., 2013. Exploiting microbial hyperthermophilicity to produce an industrial chemical, using hydrogen and carbon dioxide. Proc. Natl. Acad. Sci. U. S. A. 110, 5840-5845. doi:10.1073/pnas.1222607110

Keshav, A., Wasewar, K.L., 2010. Back extraction of propionic acid from loaded organic phase. Chem. Eng. Sci. 65, 2751-2757. doi:10.1016/J.CES.2010.01.010

Kildegaard, K.R., Jensen, N.B., Schneider, K., Czarnotta, E., Oezdemir, E., Klein, T., Maury, J., Ebert, B.E., Christensen, H.B., Chen, Y., Kim, I.-K., Herrgard, M.J., Blank, L.M., Forster, J., Nielsen, J., Borodina, I., 2016. Engineering and systems-level analysis of Saccharomyces cerevisiae for production of 3-hydroxypropionic acid via malonyl-CoA reductase-dependent pathway. Microb. Cell Fact. 15, 609-620. doi:10.1186/s12934-0160451-5

Kildegaard, K.R., Wang, Z., Chen, Y., Nielsen, J., Borodina, I., 2015. Production of 3hydroxypropionic acid from glucose and xylose by metabolically engineered Saccharomyces cerevisiae. Metab. Eng. Commun. 2, 132-136. doi:10.1016/j.meteno.2015.10.001 
Kim, C., Kim, M.Y., Iain, M., Jeon, B.-H., Premier, G.C., Park, S., Kim, J.R., 2017. Anodic electro-fermentation of 3-hydroxypropionic acid from glycerol by recombinant Klebsiella pneumoniae L17 in a bioelectrochemical system. Biotechnol. Biofuels 10. doi:10.1186/s13068-017-0886-X

Kim, K., Kim, S.-K., Park, Y.-C., Seo, J.-H., 2014. Enhanced production of 3hydroxypropionic acid from glycerol by modulation of glycerol metabolism in recombinant Escherichia coli. Bioresour. Technol. 156, 170-175. doi:10.1016/j.biortech.2014.01.009

Ko, Y., Seol, E., Sundara Sekar, B., Kwon, S., Lee, J., Park, S., 2017. Metabolic engineering of Klebsiella pneumoniae J2B for co-production of 3-hydroxypropionic acid and 1,3propanediol from glycerol: Reduction of acetate and other by-products. Bioresour. Technol. 244, 1096-1103. doi:10.1016/J.BIORTECH.2017.08.099

Krauter, H., Willke, T., Vorlop, K.-D., 2012. Production of high amounts of 3hydroxypropionaldehyde from glycerol by Lactobacillus reuteri with strongly increased biocatalyst lifetime and productivity. N. Biotechnol. 29, 211-217. doi:10.1016/j.nbt.2011.06.015

Kumar, S., Babu, B. V., Wasewar, K.L., 2012. Investigations of biocompatible systems for reactive extraction of propionic acid using aminic extractants (TOA and Aliquat 336). Biotechnol. Bioprocess Eng. 17, 1252-1260. doi:10.1007/s12257-012-0310-0

Kumar, V., Ashok, S., Park, S., 2013. Recent advances in biological production of 3hydroxypropionic acid. Biotechnol. Adv. 31, 945-961. doi:10.1016/j.biotechadv.2013.02.008

Kumar, V., Park, S., 2017. Potential and limitations of Klebsiella pneumoniae as a microbial cell factory utilizing glycerol as the carbon source. Biotechnol. Adv. 36, 150-167. doi:10.1016/j.biotechadv.2017.10.004

Lan, E.I., Chuang, D.S., Shen, C.R., Lee, A.M., Ro, S.Y., Liao, J.C., 2015. Metabolic engineering of cyanobacteria for photosynthetic 3-hydroxypropionic acid production from CO2 using Synechococcus elongatus PCC 7942. Metab. Eng. 31, 163-170. doi:10.1016/j.ymben.2015.08.002

Lee, S.-H., Park, S.J., Park, O.-J., Cho, J., Rhee, J.W., 2009. Production of 3Hydroxypropionic Acid from Acrylic Acid by Newly Isolated Rhodococcus erythropolis LG12. J. Microbiol. Biotechnol. 19, 474-481. doi:10.4014/jmb.0808.473

Li, J., Zong, H., Zhuge, B., Lu, X., Fang, H., Sun, J., 2016. Immobilization of Acetobacter sp. CGMCC 8142 for efficient biocatalysis of 1, 3-propanediol to 3-hydroxypropionic acid. 
Biotechnol. Bioprocess Eng. 21, 523-530. doi:10.1007/s12257-016-0022-y

Li, S., Si, T., Wang, M., Zhao, H., 2015. Development of a Synthetic Malonyl-CoA Sensor in Saccharomyces cerevisiae for Intracellular Metabolite Monitoring and Genetic Screening. ACS Synth. Biol. 4, 1308-1315. doi:10.1021/acssynbio.5b00069

Li, Y., Ge, X.-Z., Tian, P.-F., 2017. Production of 1,3-propanediol from glycerol using a new isolate Klebsiella sp. AA405 carrying low levels of virulence factors. Biotechnol. Biotechnol. Equip. 1-8. doi:10.1080/13102818.2017.1335175

Li, Y., Su, M., Ge, X., Tian, P., 2013. Enhanced aldehyde dehydrogenase activity by regenerating $\mathrm{NAD}(+)$ in Klebsiella pneumoniae and implications for the glycerol dissimilation pathways. Biotechnol. Lett. 35, 1609-1615. doi:10.1007/s10529-013-12431

Li, Y., Wang, X., Ge, X., Tian, P., 2016. High Production of 3-Hydroxypropionic Acid in Klebsiella pneumoniae by Systematic Optimization of Glycerol Metabolism. Sci. Rep. 6, 26932. doi:10.1038/srep26932

Lian, H., Zeldes, B.M., Lipscomb, G.L., Hawkins, A.B., Han, Y., Loder, A.J., Nishiyama, D., Adams, M.W.W., Kelly, R.M., 2016. Ancillary contributions of heterologous biotin protein ligase and carbonic anhydrase for $\mathrm{CO} 2$ incorporation into 3-hydroxypropionate by metabolically engineered Pyrococcus furiosus. Biotechnol. Bioeng. 113, 2652-2660. doi:10.1002/bit.26033

Liao, H.H., Gokarn, R.R., Gort, S.J., Jessen, H., Selifonova, O. V., 2005. Production of 3hydroxypropionic acid using beta-alanine/pyruvate aminotransferase. WO2005118719 A2.

Lim, H.G., Noh, M.H., Jeong, J.H., Park, S., Jung, G.Y., 2016. Optimum Rebalancing of the 3-Hydroxypropionic Acid Production Pathway from Glycerol in Escherichia coli. ACS Synth. Biol. 5, 1247-1255. doi:10.1021/acssynbio.5b00303

Liu, C., Ding, Y., Xian, M., Liu, M., Liu, H., Ma, Q., Zhao, G., 2017. Malonyl-CoA pathway: a promising route for 3-hydroxypropionate biosynthesis. Crit. Rev. Biotechnol. 37, 933941. doi:10.1080/07388551.2016.1272093

Liu, C., Ding, Y., Zhang, R., Liu, H., Xian, M., Zhao, G., 2016. Functional balance between enzymes in malonyl-CoA pathway for 3-hydroxypropionate biosynthesis. Metab. Eng. 34, 104-111. doi:10.1016/J.YMBEN.2016.01.001

Liu, M., Yao, L., Xian, M., Ding, Y., Liu, H., Zhao, G., 2016. Deletion of arcA increased the production of acetyl-CoA-derived chemicals in recombinant Escherichia coli. Biotechnol. Lett. 38, 97-101. doi:10.1007/s10529-015-1953-7 
Liu, S., 2017. Chapter 12 - Cell Cultivation, in: Liu, S. (Ed.), Bioprocess Engineering (Second Edition). Elsevier, pp. 699-782. doi:http://dx.doi.org/10.1016/B978-0-444-63783$3.00012-5$

Loh, K.D., Gyaneshwar, P., Papadimitriou, E.M., Fong, R., Kim, K.-S.S., Parales, R., Zhou, Z., Inwood, W., Kustu, S., 2006. A previously undescribed pathway for pyrimidine catabolism. Proc. Natl. Acad. Sci. U. S. A. 103, 5114-5119. doi:10.1073/pnas.0600521103

López-Garzón, C.S., Straathof, A.J.J., 2014. Recovery of carboxylic acids produced by fermentation. Biotechnol. Adv. 32, 873-904. doi:10.1016/j.biotechadv.2014.04.002 Luo, H., Zhou, D., Liu, X., Nie, Z., Quiroga-Sánchez, D.L., Chang, Y., 2016. Production of 3Hydroxypropionic Acid via the Propionyl-CoA Pathway Using Recombinant Escherichia coli Strains. PLoS One 11, e0156286. doi:10.1371/journal.pone.0156286

Lynch, M.D., Gill, R.T., Warnecke-Lipscomb, T., 2011. Method for producing 3hydroxypropionic acid and other products. WO 2011/038364 A1.

Matsakas, L., Topakas, E., Christakopoulos, P., 2014. New Trends in Microbial Production of 3-hydroxypropionic Acid. Curr. Biochem. Eng. 1, 141-154. doi:10.2174/2212711901666140415200133

Mavrovouniotis, M.L., 1996. Duality theory for thermodynamic bottlenecks in bioreaction pathways. Chem. Eng. Sci. 51, 1495-1507. doi:10.1016/0009-2509(95)00308-8

Meng, X., Tsobanakis, P., Abraham, T., 2006. Process for separating and recovering 3hydroxypropionic acid and acrylic acid. US20060149100 A1.

Moscoviz, R., Toledo-Alarcón, J., Trably, E., Bernet, N., 2016a. Electro-Fermentation: How To Drive Fermentation Using Electrochemical Systems. Trends Biotechnol. 34, 856865. doi:10.1016/j.tibtech.2016.04.009

Moscoviz, R., Trably, E., Bernet, N., 2016b. Consistent 1,3-propanediol production from glycerol in mixed culture fermentation over a wide range of $\mathrm{pH}$. Biotechnol. Biofuels 9. doi:10.1186/s13068-016-0447-8

Moussa, M., Burgé, G., Chemarin, F., Bounader, R., Saulou-Bérion, C., Allais, F., Spinnler, H.-E., Athès, V., 2015. Reactive extraction of 3-hydroxypropionic acid from model aqueous solutions and real bioconversion media. Comparison with its isomer 2hydroxypropionic (lactic) acid. J. Chem. Technol. Biotechnol. 91, 2276-2285. doi: $10.1002 /$ jetb.4813

Murali, N., Srinivas, K., Ahring, B.K., 2017. Biochemical Production and Separation of Carboxylic Acids for Biorefinery Applications. Fermentation 3, 22. 
doi:10.3390/fermentation3020022

Nakamura, S., Kunioka, M., Doi, Y., 1991. Biosynthesis and characterization of bacterial poly(3-hydroxybutyrate-co-3-hydroxyprioniate). J. Macromol. Sci. A28, 15-24. doi:10.1080/00222339108054378

O’Brien, J.R., Raynaud, C., Croux, C., Girbal, L., Soucaille, P., Lanzilotta, W.N., 2004. Insight into the Mechanism of the B12-Independent Glycerol Dehydratase from Clostridium butyricum: Preliminary Biochemical and Structural Characterization. Biochemistry 43, 4635-4645. doi:10.1021/BI035930K

Park, J.M., Park, J.Y., Park, W.C., Lee, S.M., Seo, Y. Bin, 2016. Recombinant Yeast Producing 3-Hydroxypropionic Acid and Method for Producing 3-Hydroxypropionic Acid Using the Same. WO2016032279.

Pasteur, L., 1864. Mémoire sur la fermentation acétique. Ann. Sci. l'Ecole Norm. Supérieure 1ère série, $113-158$.

Podschun, R., Ullmann, U., 1998. Klebsiella spp. as nosocomial pathogens: epidemiology, taxonomy, typing methods, and pathogenicity factors. Clin. Microbiol. Rev. 11, 589603.

Raj, S.M., Rathnasingh, C., Jung, W.-C., Park, S., 2009. Effect of process parameters on 3hydroxypropionic acid production from glycerol using a recombinant Escherichia coli. Appl. Microbiol. Biotechnol. 84, 649-657. doi:10.1007/s00253-009-1986-8

Raj, S.M., Rathnasingh, C., Jung, W.-C., Selvakumar, E., Park, S., 2010. A Novel NAD+dependent aldehyde dehydrogenase encoded by the puuC gene of Klebsiella pneumoniae DSM 2026 that utilizes 3-hydroxypropionaldehyde as a substrate. Biotechnol. Bioprocess Eng. 15, 131-138. doi:10.1007/s12257-010-0030-2

Raspor, P., Goranovič, D., 2008. Biotechnological Applications of Acetic Acid Bacteria. Crit. Rev. Biotechnol. 28, 101-124. doi:10.1080/07388550802046749

Rogers, J.K., Church, G.M., 2016. Genetically encoded sensors enable real-time observation of metabolite production. Proc. Natl. Acad. Sci. U. S. A. 113, 2388-2393. doi:10.1073/pnas. 1600375113

Rychen, G., Aquilina, G., Azimonti, G., Bampidis, V., De Lourdes Bastos, M., Bories, G., Chesson, A., Cocconcelli, P.S., Flachowski, G., Gropp, J., Kolar, B., Kouba, M., López Alonso, M., López Puente, S., Mantovani, A., Mayo, B., Ramos, F., Villa, R.E., Wallace, R.J., Wester, P., Brozzi, R., Saarela, M., 2017. Safety and efficacy of Bacillus subtilis PB6 (Bacillus subtilis ATCC PTA-6737) as a feed additive for sows. EFSA J. 15, 48554864. doi:10.2903/j.efsa.2017.4855 
Sabet-Azad, R., Sardari, R.R.R., Linares-Pastén, J.A., Hatti-Kaul, R., 2015. Production of 3hydroxypropionic acid from 3-hydroxypropionaldehyde by recombinant Escherichia coli co-expressing Lactobacillus reuteri propanediol utilization enzymes. Bioresour. Technol. 180, 214-221. doi:10.1016/j.biortech.2014.12.109

Saini, R., Kapoor, R., Kumar, R., Siddiqi, T.O., Kumar, A., 2011. CO2 utilizing microbes A comprehensive review. Biotechnol. Adv. 29, 949-960.

doi:10.1016/j.biotechadv.2011.08.009

Sankaranarayanan, M., Ashok, S., Park, S., 2014. Production of 3-hydroxypropionic acid from glycerol by acid tolerant Escherichia coli. J. Ind. Microbiol. Biotechnol. 41, 10391050. doi:10.1007/s10295-014-1451-2

Sankaranarayanan, M., Somasundar, A., Seol, E., Chauhan, A.S., Kwon, S., Jung, G.Y., Park, S., 2017. Production of 3-hydroxypropionic acid by balancing the pathway enzymes using synthetic cassette architecture. J. Biotechnol. 259, 140-147. doi:10.1016/j.jbiotec.2017.07.027

Sardari, R.R.R., Dishisha, T., Pyo, S.-H., Hatti-Kaul, R., 2013. Biotransformation of glycerol to 3-hydroxypropionaldehyde: Improved production by in situ complexation with bisulfite in a fed-batch mode and separation on anion exchanger. J. Biotechnol. 168, 534-542. doi:10.1016/j.jbiotec.2013.09.009

Schievano, A., Pepé Sciarria, T., Vanbroekoven, K., De Wever, H., Puig, S., Andersen, S.J., Rabaey, K., Pant, D., 2016. Electro-fermentation - Merging electrochemistry with fermentation in industrial applications. Trends Biotechnol. in press, 1-13. doi:10.1016/j.tibtech.2016.04.007

Schwarz, M., Köpcke, B., Weber, R.W.S., Sterner, O., Anke, H., 2004. 3-Hydroxypropionic acid as a nematicidal principle in endophytic fungi. Phytochemistry 65, 2239-2245. doi:10.1016/j.phytochem.2004.06.035

Sobolov, M., Smiley, K.L., 1960. Metabolism of glycerol by an acrolein-forming Lactobacillus. J. Bacteriol. 79, 261-266.

Song, C.W., Kim, J.W., Cho, I.J., Lee, S.Y., 2016. Metabolic Engineering of Escherichia coli for the Production of 3-Hydroxypropionic Acid and Malonic Acid through beta-Alanine Route. ACS Synth. Biol. 5, 1256-1263. doi:10.1021/acssynbio.6b00007

Sriramulu, D.D., Liang, M., Hernandez-Romero, D., Raux-Deery, E., Lünsdorf, H., Parsons, J.B., Warren, M.J., Prentice, M.B., 2008. Lactobacillus reuteri DSM 20016 produces cobalamin-dependent diol dehydratase in metabolosomes and metabolizes 1,2propanediol by disproportionation. J. Bacteriol. 190, 4559-67. doi:10.1128/JB.01535-07 
Straathof, A.J.J., 2011. The Proportion of Downstream Costs in Fermentative Production Processes, in: Comprehensive Biotechnology. Elsvier, pp. 811-814.

Suthers, P.F., Cameron, D.C., 2001. Production of 3-hydroxypropionic acid in recombinant organisms. WO 01/16346 A1.

Suyama, A., Higuchi, Y., Urushihara, M., Maeda, Y., Takegawa, K., 2017. Production of 3hydroxypropionic acid via the malonyl-CoA pathway using recombinant fission yeast strains. J. Biosci. Bioeng. 124, 392-399. doi:10.1016/j.jbiosc.2017.04.015

Takamizawa, K., Horitsu, H., Ichikawa, T., Kawai, K., Suzuki, T., 1993. $\beta$-hydroxypropionic acid production by Byssochlamys sp. grown on acrylic acid. Appl. Microbiol. Biotechnol. 40, 196-200. doi:10.1007/BF00170365

Talarico, T.L., Axelsson, L.T., Novotny, J., Fiuzat, M., Dobrogosz1, W.J., 1990. Utilization of Glycerol as a Hydrogen Acceptor by Lactobacillus reuteri: Purification of 1,3Propanediol:NAD+ Oxidoreductase. Appl. Environ. Microbiol. 56, 943-948.

Talarico, T.L., Casas, I.A., Chung, T.C., Dobrogosz, W.J., 1988. Production and isolation of reuterin, a growth inhibitor produced by Lactobacillus reuteri. Antimicrob. Agents Chemother. 32, 1854-1858. doi:10.1128/AAC.32.12.1854

Talarico, T.L., Dobrogosz, W.J., 1990. Purification and Characterization of Glycerol Dehydratase from Lactobacillus reuteri. Appl. Environ. Microbiol. 56, 1195-1197.

Talarico, T.L., Dobrogosz, W.J., 1989. Chemical characterization of an antimicrobial substance produced by Lactobacillus reuteri. Antimicrob. Agents Chemother. 33, 674679.

Tamada, J.A., King, C.J., 1990. Extraction of carboxylic acids with amine extractants. 2. Chemical interactions and interpretation of data. Ind. Eng. Chem. Res. 29, 1327-1333. doi:10.1021/ie00103a036

Tassone, M., Diano, A., 2017. Beta-alanine aminotransferases for the production of 3hydroxypropionic acid. WO2017035270 A1.

Tengler, R., DeCoster, D., 2013. Purification of 3-Hydroxypropionic Acid from Crude Cell Broth and Production of Acrylamide. US20130345470 A1.

Tkac, J., Svitel, J., Vostiar, I., Navratil, M., Gemeiner, P., 2009. Membrane-bound dehydrogenases from Gluconobacter sp.: Interfacial electrochemistry and direct bioelectrocatalysis. Bioelectrochemistry 76, 53-62. doi:10.1016/j.bioelechem.2009.02.013

Tokuyama, K., Ohno, S., Yoshikawa, K., Hirasawa, T., Tanaka, S., Furusawa, C., Shimizu, H., 2014. Increased 3-hydroxypropionic acid production from glycerol, by modification 
of central metabolism in Escherichia coli. Microb. Cell Fact. 13. doi:10.1186/14752859-13-64

Tsuruno, K., Honjo, H., Hanai, T., 2015. Enhancement of 3-hydroxypropionic acid production from glycerol by using a metabolic toggle switch. Microb. Cell Fact. 14. doi:10.1186/s12934-015-0342-1

van Maris, A.J.A., Konings, W.N., van Dijken, J.P., Pronk, J.T., 2004. Microbial export of lactic and 3-hydroxypropanoic acid: implications for industrial fermentation processes. Metab. Eng. 6, 245-255. doi:10.1016/j.ymben.2004.05.001

Velasquez, J.E., Collias, D.I., Godlewski, J.E., 2017. Catalytic Dehydration of Hydroxypropionic Acid and its Derivatives. WO2017040386 A1.

Wang, B., Shao, Y., Chen, F., 2015. Overview on mechanisms of acetic acid resistance in acetic acid bacteria. World J. Microbiol. Biotechnol. 31, 255-263. doi:10.1007/s11274015-1799-0

Wang, K., Tian, P., 2017. Engineering Plasmid-Free Klebsiella pneumoniae for Production of 3-Hydroxypropionic Acid. Curr. Microbiol. 74, 55-58. doi:10.1007/s00284-016-1153-2

Wang, Y., Chen, L., Zhang, W., 2016a. Proteomic and metabolomic analyses reveal metabolic responses to 3-hydroxypropionic acid synthesized internally in cyanobacterium Synechocystis sp. PCC 6803. Biotechnol. Biofuels 9. doi:10.1186/s13068-016-0627-6

Wang, Y., Ichikawa, M., Cao, A., Yoshie, N., Inoue, Y., 1999. Comonomer composition distribution of $\mathrm{P}(3 \mathrm{HB}-\mathrm{co}-3 \mathrm{HP}) \mathrm{s}$ produced by Alcaligenes latus at several $\mathrm{pH}$ conditions. Macromol. Chem. Phys. 200, 1047-1053.

Wang, Y., Inagawa, Y., Saito, T., Kasuya, K., Doi, Y., Inoue, Y., 2002. Enzymatic hydrolysis of bacterial poly(3-hydroxybutyrate-co-3-hydroxypropionate)s by poly(3hydroxyalkanoate) depolymerase from Acidovorax Sp TP4. Biomacromolecules 3, 828834. doi:10.1021/bm020019p

Wang, Y., Sun, T., Gao, X., Shi, M., Wu, L., Chen, L., Zhang, W., 2016b. Biosynthesis of platform chemical 3-hydroxypropionic acid (3-HP) directly from $\mathrm{CO} 2$ in cyanobacterium Synechocystis sp. PCC 6803. Metab. Eng. 34, 60-70. doi:10.1016/j.ymben.2015.10.008

Wang, Y., Tao, F., Ni, J., Li, C., Xu, P., 2015. Production of C3 platform chemicals from $\mathrm{CO} 2$ by genetically engineered cyanobacteria. Green Chem. 17, 3100-3110. doi: $10.1039 / \mathrm{c} 5 \mathrm{gc00129c}$

Wasewar, K.L., Yawalkar, A.A., Moulijn, J.A., Pangarkar, V.G., 2004. Fermentation of Glucose to Lactic Acid Coupled with Reactive Extraction: A Review. Ind. Eng. Chem. 
Res. 43, 5969-5982. doi:10.1021/ie049963n

Werpy, T., Petersen, G., 2004. Top Value Added Chemicals from Biomass: Volume I -Results of Screening for Potential Candidates from Sugars and Synthesis Gas., US Department of Energy. doi:10.2172/15008859

Yang, Y.-M., Chen, W.-J., Yang, J., Zhou, Y.-M., Hu, B., Zhang, M., Zhu, L.-P., Wang, G.Y., Yang, S., 2017. Production of 3-hydroxypropionic acid in engineered Methylobacterium extorquens AM1 and its reassimilation through a reductive route. Microb. Cell Fact. 16, 179. doi:10.1186/s12934-017-0798-2

Yankov, D., Molinier, J., Albet, J., Malmary, G., Kyuchoukov, G., 2004. Lactic acid extraction from aqueous solutions with tri-n-octylamine dissolved in decanol and dodecane. Biochem. Eng. J. 21, 63-71. doi:10.1016/j.bej.2004.03.006

Ye, Z., Li, X., Cheng, Y., Liu, Z., Tan, G., Zhu, F., Fu, S., Deng, Z., Liu, T., 2016. Evaluation of 3-hydroxypropionate biosynthesis in vitro by partial introduction of the 3hydroxypropionate/4-hydroxybutyrate cycle from Metallosphaera sedula. J. Ind. Microbiol. Biotechnol. 43, 1313-1321. doi:10.1007/s10295-016-1793-Z

Yu, S., Yao, P., Li, J., Ren, J., Yuan, J., Feng, J., Wang, M., Wu, Q., Zhu, D., 2016. Enzymatic synthesis of 3-hydroxypropionic acid at high productivity by using free or immobilized cells of recombinant Escherichia coli. J. Mol. Catal. B-ENZYMATIC 129, 37-42. doi:10.1016/j.molcatb.2016.03.011

Zaushitsyna, O., Dishisha, T., Hatti-Kaul, R., Mattiasson, B., 2017. Crosslinked, cryostructured Lactobacillus reuteri monoliths for production of 3hydroxypropionaldehyde, 3-hydroxypropionic acid and 1,3-propanediol from glycerol. J. Biotechnol. 241, 22-32. doi:10.1016/j.jbiotec.2016.11.005

Zhang, Q., Gong, J.-S., Dong, T.-T., Liu, T.-T., Li, H., Dou, W.-F., Lu, Z.-M., Shi, J.-S., Xu, Z.-H., 2017. Nitrile-hydrolyzing enzyme from Meyerozyma guilliermondii and its potential in biosynthesis of 3-hydroxypropionic acid. Bioprocess Biosyst. Eng. 40, 901910. doi:10.1007/s00449-017-1754-6

Zhang, X.-Z., Zhang, Y.-H.P., 2010. One-step production of biocommodities from lignocellulosic biomass by recombinant cellulolytic Bacillus subtilis: Opportunities and challenges. Eng. Life Sci. 10, 398-406. doi:10.1002/elsc.201000011

Zhao, L., Lin, J., Wang, H., Xie, J., Wei, D., 2015. Development of a two-step process for production of 3-hydroxypropionic acid from glycerol using Klebsiella pneumoniae and Gluconobacter oxydans. Bioprocess Biosyst. Eng. 38, 2487-2495. doi:10.1007/s00449015-1486-4 
1611 Zhou, S., Catherine, C., Rathnasingh, C., Somasundar, A., Park, S., 2013. Production of 31612 Hydroxypropionic Acid From Glycerol by Recombinant Pseudomonas denitrificans.

1613 Biotechnol. Bioeng. 110, 3177-3187. doi:10.1002/bit.24980

1614 


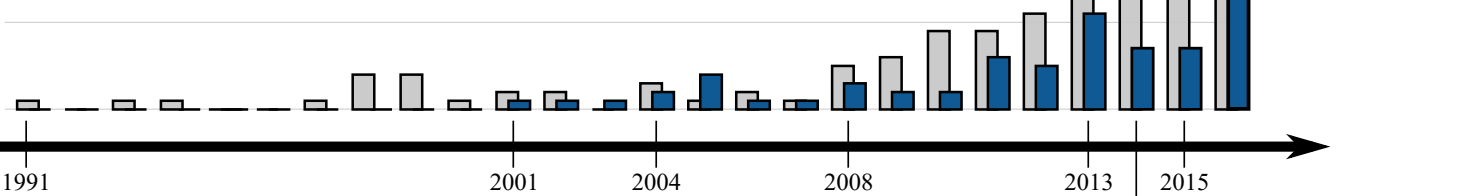

Biosynthesis and

characterisation of poly (3-

hydroxybutyrate-co-3-

hydroxypropionate)

\section{$1^{\text {rst }}$ patent on 3-HP production from glycerol \\ in recombinant bacterial hosts \\ DoE report: 3 -HP listed as a promising \\ building-block}

\begin{tabular}{|l|} 
3-HP production from \\
$\mathrm{H}_{2}$ and $\mathrm{CO}_{2}$ by \\
Pyrococcus furiosus
\end{tabular}

3-HP found as an end-product of lactic acid bacteria metabolism
2014

3-HP production through an integrated process involving $L$. reuteri and Gluconobacter oxydans

First attempts at producing 3-HP from xylose

Reactive extraction of 3-HP from a

3-HP production by engineered Saccharomyces cerevisiae

Glycerol conversion to 1,3-PDO and

3-HP using Lactobacillus reuteri 


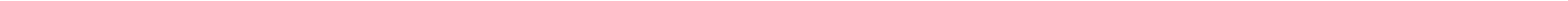




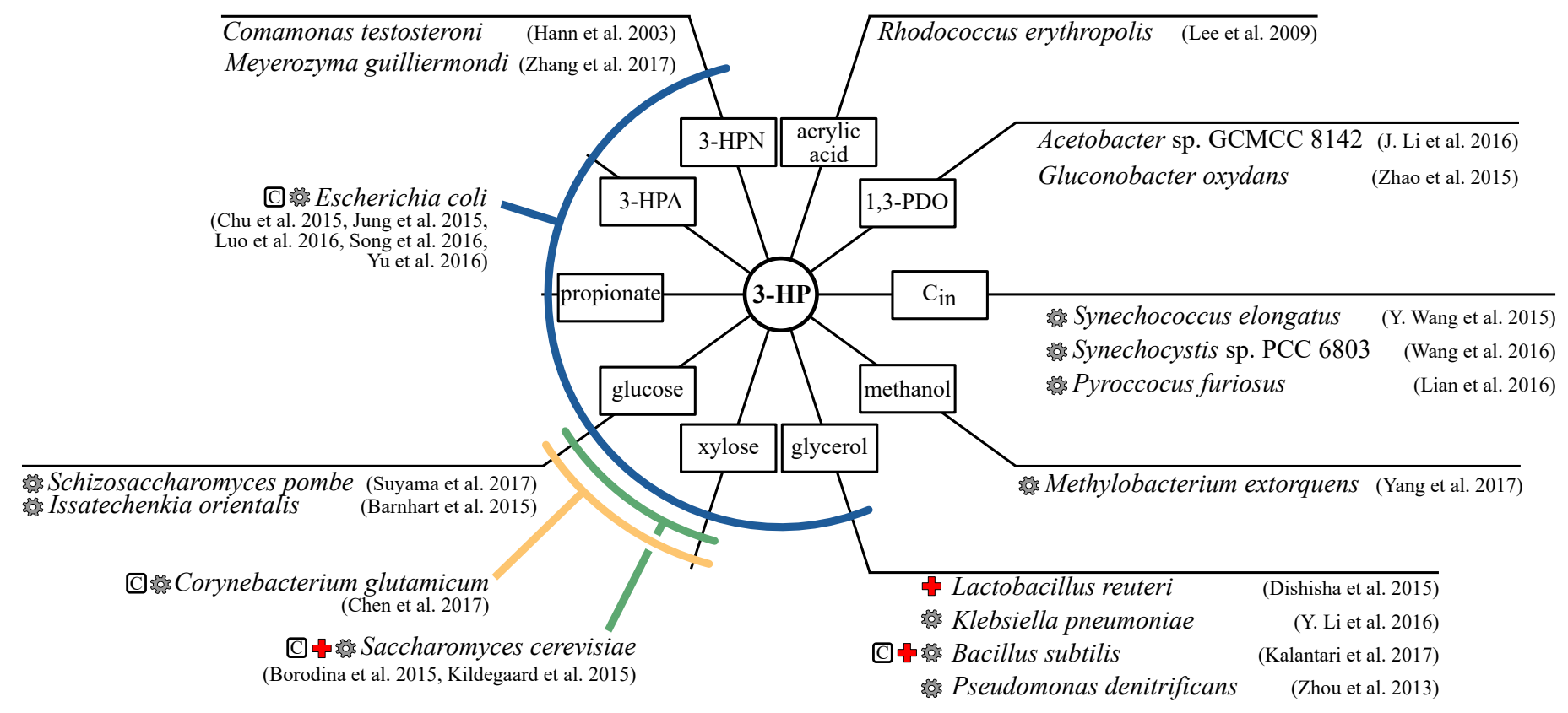



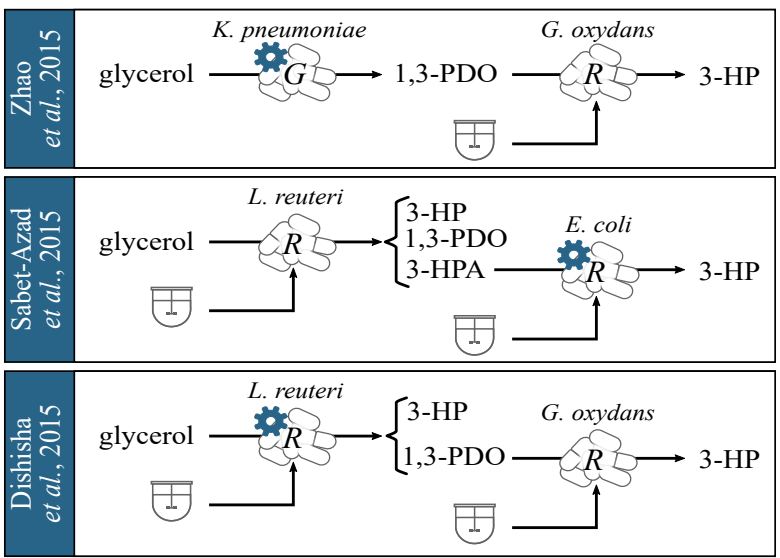

$\longrightarrow$ Resting cells

$\because$ Genetically engineered strain

$\longrightarrow$ Growing cells

(I) Biomass production step 


\section{Figure 1.}

Evolution over the years of the number of references on the Web of Science (WoS) and the number of patents concerning 3-hydroxypropionic acid bioproduction and overview of the key milestones.

\section{Figure 2.}

Main heterotrophic routes for 3-HP synthesis.

Reactions presented with stoichiometrics are displayed in blue. Reactions presented without stoichiometrics (only qualitatively) are displayed in orange. Due to the different possible variants of the $\beta$-alanine pathway, free energy release was not calculated for this pathway (see part 2.1.4).
A. Glycerol oxidation through a CoA-dependent pathway
B. Glycerol oxidation through a CoA-independent pathway
C. Malonyl-CoA pathway
D. $\beta$-Alanine pathway
E. Aerobic 1,3-PDO oxidation
F. 3-HPN hydrolysis

Abbreviations:

CoA: coenzyme A

$\mathrm{P}_{\mathrm{i}}$ inorganic phosphate $\left(\mathrm{HPO}_{4}^{2-}\right)$

3-HPA: 3-hydroxypropionaldehyde

3-HP-CoA: 3-hydroxypropionyl-coenzymeA

3-HP-P: 3-hydroxypropionyl-phosphate

1,3-PDO: 1,3-propanediol

MSA: malonic semialdehyde

TCA: tricarboxylic acid

3-HPN: 3-hydroxypropionitrile

3-HPAm: 3-hydroxypropionamide

\section{Figure 3.}

Microbial agents under investigation for 3-HP production and their carbon sources.

Genetically engineered species are indicated with a gear.

Abbreviations:

3-HPA: 3-hydroxypropionaldehyde

3-HPN: 3-hydroxypropionitrile

1,3-PDO: 1,3-propanediol

$\mathrm{C}$ in: inorganic carbon

Figure 4.

Multi-step strategies for 3-hydroxypropionic acid (3-HP) production from glycerol. 
1,3-PDO: 1,3-propanediol

3-HPA: 3-hydroxypropionaldehyde 